\title{
Cleavage and Crosslinking of Polymeric Coal Structures During Pyrolysis
}

Final Report

\author{
D.F. McMillen \\ R. Malhotra
}

February 1992

Work Performed Under Contract No.: DE-AC21-87MC23286

For

U.S. Department of Energy

Office of Fossil Energy

Morgantown Energy Technology Center

Morgantown, West Virginia

By

SRI International

Molecular Physics Laboratory

Menlo Park, California 


\section{DISCLAIMER}

This report was prepared as an account of work sponsored by an agency of the United States Government. Neither the United States Government nor any agency thereof, nor any of their employees makes any warranty, express or implied, or assumes any legal liability or responsibility for the accuracy, completeness or usefulness of any information, apparatus, product, or process disclosed, or represents that its use would not infringe privately owned rights. Reference herein to any specific commercial product, process, or service by trade name, trademark, manufacturer, or otherwise, does not necessarily constitute or imply its endorsement, recommendation, or favoring by the United States Government or any agency thereof. The views and opinions of authors expressed herein do not necessarily state or reflect those of the United States Government or any agency thereof.

This report has been reproduced directly from the best available copy.

Available to DOE and DOE contractors from the Office of Scientific and Technical Information, P.O. Box 62, Oak Ridge, TN 37831; prices available from (615)576-8401, FTS 626-8401.

Available to the public from the National Technical Information Service, U.S. Department of Conmerce, 5285 Port Royal Rd., Springfield, VA 22161. 


\title{
Cleavage and Crosslinking of Polymeric
}

Coal Structures During Pyrolysis

\author{
Final Report
}

D.F. McMillen

R. Malhotra

Work Performed Under Contract No.: DE-AC21-87MC23286

For

U.S. Department of Energy

Office of Fossil Energy

Morgantown Energy Technology Center

P.O. Box 880

Morgantown, West Virginia 26507-0880

By

SRI International

Molecular Physics Laboratory

333 Ravenswood Avenue

Menlo Park, California 94025-3493

February 1992 


\section{SUMMARY}

The ultimate objective of this project was to develop a better understanding of volatiles production to help optimize the yield and character of condensable coprodu. is during coal pyrolysis or mild gasification. The specific objectives were to

(1) Develop pyrolysis procedures that minimize secondary reactions.

(2) Develop coal pretreatments that current knowledge suggests will promote bond scission or prevent retrograde reactions.

Our approach was to study the pyrolysis of coals and tar-loaded coals by using several techniques that span a range of heating rates and pressures. Slow-heating pyrolyses were performed at low pressures in the inlet of a field ionization mass spectrometer (FIMS) and at atmospheric pressures in a thermogravimetric analyzer (TGA). Moderately rapid-heating pyrolyses were performed in a vacuum TGA apparatus and ir. sealed silica ampules heated in a molten-salt bath. The fastest heating rates were achieved with laser pyrolysis at about $30,000 \mathrm{~K} / \mathrm{s}$. This technique was developed under this program.

The significant accomplishments and findings of this research are listed below.

- We designed, assembled, and tested a laser-heated entrained-flow system that maintains a steady flow of coal particles in a fine stream traveling upward at velocities of a few centimeters per second, then efficiently separates the char from the tar in a cyclone and filter train.

- We measured particle temperatures by using optical pyrometry and imaging with an infrared video camera.

- FIMS analysis of evolved tars suggests that, under rapid heat-up conditions, a substantial portion of the tar evolution results from liquid transport rather than from an evaporative process.

- The levels of phenols and dihydroxy phenols in laser-pyrolysis tars are substantially higher than in other entrained-flow reactor tars, in part as a result of fewer retrograde reactions involving these reactive products.

- Tar production in laser pyrolysis is extremely rapid, with tar release times of less than $50 \mathrm{~ms}$ even at temperatures as low as $500^{\circ} \mathrm{C}$. This finding is particularly relevant in the context of mild gasification. 
- Tar yields are significantly higher from laser pyrolysis than from some other entrained-flow laboratory pyrolysis techniques, and the yields for subbituminous coals approach those for bituminous coals, in contrast to the case with slower heating methods, from which the yields for subbituminous coals tend to be much lower.

- With slow-heating pyrolysis techniques, tar pretreatment did not result in improved volatiles yields; but with a "rapid"-heating vacuum TGA technique, $10 \%$ to $30 \%$ increases in volatiles yields were observed for three different coals.

- Pyrolysis in a tubing bomb using a molten-salt bath at $490^{\circ} \mathrm{C}$ did not result in significantly enhanced tar yields from an Illinois No. 6 coal loaded with partially hydrogenated coal tar or hexahydropyrene.

- With laser pyrolysis, tar pretreatment results in a $20 \%$ decrease in volatiles yields from an Illinois No. 6 coal but a $20 \%$ increase from a Pittsburgh coal when the steady-state temperature is in the region of $840^{\circ}-880^{\circ} \mathrm{C}$.

The rates and temperature dependence observed during laser pyrolysis of coal are not reconcilable with activation energies for tar generation as high as to 30 to $50 \mathrm{kcal} / \mathrm{mol}$ often reported for ramped-temperature coal pyrolysis. Furth rmore, the very rapid laser-heating we have used approximates a temperature-jump condirion where the widely used model of distributed activation energies for a set of parallel first-order reactions can no longer be a valid explanation for apparent activation energies lower than those expected for any of the individual first order reactions. In other words, the data obtained here appear incompatible with individual component activation energies in the 50 to $65 \mathrm{kcal} / \mathrm{mol}$ range that would be representative of rate limitation by weak-bond homolysis. On the other hand, the results are generally supportive of a mechanistic picture in which tar generation doe not result form spontaneous thermal scission of weak bonds, but is the result of a complex sequence of hydrogen-transfer reactions.

The high tar yield seen in this work, where the entire volume of the coal particle becomes hot and fluid at very nearly the same time, taken together with the evident non-vapor transport of the tar under these conditions, emphasizes the importance of better understanding the development of fluidity during coal heating. This specifically includes the profound effects-long-recognized but poorly understood - that mild oxidation has in suppressing coal fluidity. It also includes the more recently recognized fact that heating in the presence of an inert gas produced substantially greater fluidity than does heating in the presence of combustion gases, even if the conditions are very fuel rich and all the oxygen itself has already been consumed when the coal particles are encountered. A better understanding of these fluidity phenomena carries substantial implications for improvement of mild gasification under practical oxidation conditions. 
In more general terms, if one wishes to have engineering models for volatiles production (whether they are to be used for guiding experimental work in pulverized coal combustion or wh ther they are to be used for process improvement in mild gasification) that are based on a correct picture of the chemistry of tar generation and transport, then these results clearly call for further coal pyrolysis studies with well controlled, very rapid radiant heating, but with temperature measurement improved further, from what we were able to accomplish within this project. 


\section{CONTENTS}

SUMMAR Y .................................................................. i

ILLUSTRATIONS ............................................................. vi

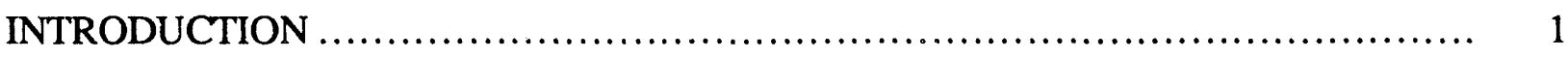

Background .................................................................... 1

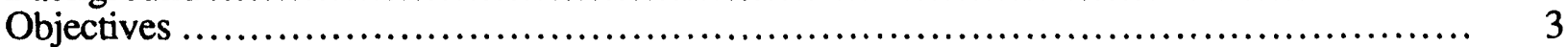

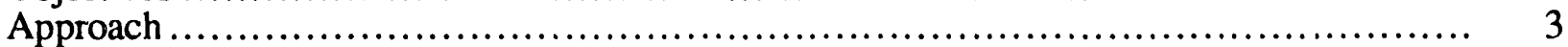

Relevance to DOE Mission........................................................ 4

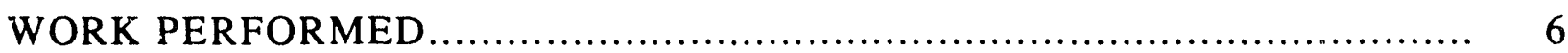

Slow Pyrolysis in FIMS .......................................................... 6

Moderately Fast Pyrolysis in Vacuum TGA............................................ 7

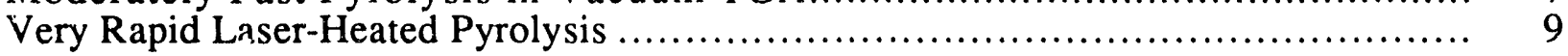

Laser-Pyrolysis Apparatus............................................... 10

Characterization of Velocity, Particle Size, and Temperature ..................... 15

Particle Temperature Measurement............................................ 19

Effect of Temperature on Tar Yield and Character............................. 23

Mechanisms of Tar Transport............................................. 27

Comparison with Other Laser-Heated Coal Pyrolysis Approaches ................ 30

Comparison with Pyrolysis Data from the Literature ........................... 31

Issues in Particle Temperature Measurement ................................... 36

Rapid Batch Pyrolysis to Intermediate Temperatures ............................. 48

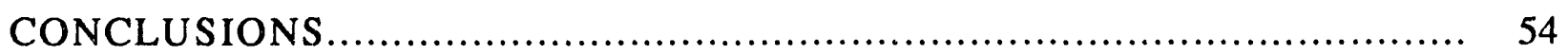

PUBLICATIONS RESULTING FROM THIS PROJECT $\ldots \ldots \ldots \ldots \ldots \ldots \ldots \ldots \ldots \ldots . . \ldots$

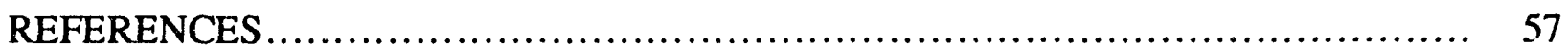




\section{ILLUSTRATIONS}

1. Scheme summarizing how PCAHs tend to increase H-utilization efficiency.......... 2

2. Schematic of entrained-flow laser pyrolysis apparatus....................... 11

3. Schematic showing the geometry of the channel integrator optics relative to particle flow and the acrylic plate burn patterns produced by the original and modified beams.

4. Top view of laser-pyrolysis cell showing reimaging of integrator output to produce two-sided heating of the particle stream.

5. Schematic of ejector-collector sheath geometry.

6. Photographs showing frame-to-frame displacement of the tar aerosol clouds ejected from pyrolyzing coal particles.

7. Operation of Model 600 Radiometer in fast line-scan mode

8. Particle-size distribution of coal particles recovered from a cold-flow experiment and char particles recovered from laser pyrolysis

9. Particle-size distribution of coal, coal entrained under cold-flow conditions, and coal char, compared with the temperature distribution measured during pyrolysis.

10. Temperature profile of the particles in the laser-pyrolysis cell.

11. Effect of particle temperature on tar yield from raw and pretreated coals.

12. Photographs of the tar filter cake produced from laser pyrolysis

13. Comparison of kinetic data for tar (or total volatiles yields) in coal pyrolysis taken from literature sources.

14. Slit response function for horizontal scanning of vertical slits (SRFdiam), as a function of slit width, using Inframetrics Model 600 equipped with $3 \mathrm{X}$ telephoto and 6-in. close-up lens (data from Inframetrics, Inc.).

15. Temperatures measured with the Inframetrics Model 600 as a function of true temperatures for a black body viewed through a range of hole sizes chosen to mimic micron-sized objects.

16. Raw temperatures determined with the Inframetrics Model 600 for an unmasked graphite body of known temperature by viewing through all optics used in looking into the pyrolysis cell. 


\section{INTRODUCTION}

\section{BACKGROUND}

In the search for efficient ways to convert coals to liquid fuels or other hydrocarbon products, the relative simplicity of pyrolysis has long been recognized as a very attractive feature. However, char yields are typically high and volatile products are generally dominated by light hydrocarbons and tars that can be extremely difficult to upgrade. Efforts to improve yields from pyrolysis processes have been hampered by the acceptance of a traditional mechanism that is, at best, incomplete. ${ }^{1}$

Recent literature results clearly show that (1) bond scission during liquefaction and pyrolysis is not limited to the traditionally postulated spontaneous thermal scission, and (2) critical retrogressive reactions do not consist of simple recombinations of thermally generated fragment radicals. ${ }^{1,2}$ Thus, bond scission and retrogression are not inextricably linked and are subject, in principle, to independent manipulation by approaches not limited to the application of heat or the use of scavengers, respectively.

The specific pretreatment we tested calls for loading coals with tars rich in polycyclic aromatic hydrocarbons (PCAHs). In earlier work performed for the Department of Energy, Pittsburgh Energy Technology Center (DOE-PETC), Contract No. DE-FG-22-86PC90908, we showed that the presence of PCAHs in liquefaction solvent increases the efficiency with which hydrogen is used to engender bond cleavage reactions. In the context of mild gasification, efficient use of hydrogen is even more crucial because the available hydrogen is limited to that present in the coal itself. Figure 1 summarizes how PCAHs increase the efficiency of hydrogen use: PCAHs recover hydrogen atoms that are transferred to positions where no linkage cleavage can occur.

Initial results of Hüttinger and Sperling on the pyrolysis of coals loaded with aromatics and hydroaromatics, ${ }^{3}$ reported shortly after the inception of this project, and more recent work by Miura et al. ${ }^{4}$ provides additional support for such an approach. These studies are limited to additives that have low molecular weights (e.g., naphthalene, tetralin, fluorene) and therefore do not include the types of PCAH structures known to form the basis for more effective liquefaction agents (e.g., phenanthrene, pyrene). Further general support for this approach comes from the well-known impact of tars on the thermoplastic behavior of coals, 5 because the ability to produce 

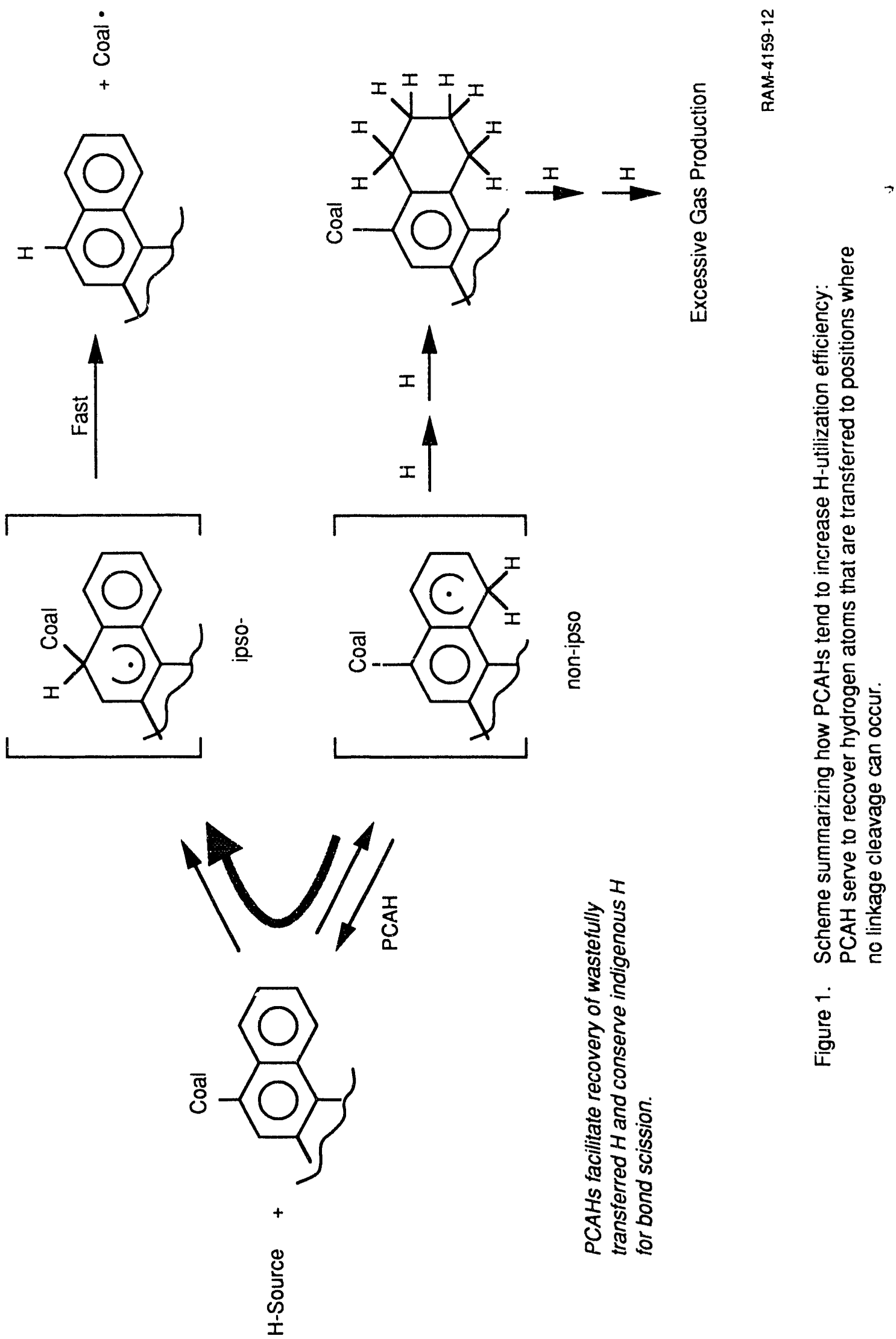
and maintain a liquid or "metaplast" state is clearly the key to volatiles production during coal heating.

\section{OBJECTIVES}

The ultimate objective of this project was to develop a better understanding of volatiles production to help optimize the yield and character of condensible coproducts during coal pyrolysis or mild gasification. The specific objectives were to

(1) Develop pyrolysis procedures that minimize secondary reactions. Several pyrolysis procedures were used. Two unique procedures were pyrolysis in the temperatureprogrammed source of a field ionization mass spectrometer (Py-FIMS) and laser pyrolysis of a stream of coal particles entrained in cold argon gas.

(2) Develop coal pretreatments that current knowledge suggests will promote bond scission, prevent retrograde reactions, or both.

\section{APPROACH}

Our approach was to study the pyrolysis of coals and tar-loaded coals by using several techniques that span a range of heating rates and pressures. Slow-heating pyrolyses (about $3^{\circ} \mathrm{C} / \mathrm{min}$ ) were performed at low pressures (in the inlet of a field ionization mass spectrometer) and at atmospheric pressures in a thermogravimetric analyzer (TGA). Moderately rapid-heating pyrolyses $\left(600^{\circ} \mathrm{C} / \mathrm{min}\right)$ were performed in a vacuum TGA apparatus and in sealed silica ampules heated in a molten-salt bath. The fastest heating rates were achieved with laser pyrolysis at about $30,000 \mathrm{~K} / \mathrm{s}$. This technique was developed under this program.

We chose to use the pyrolysis techniques listed (in addition to laser pyrolysis) on the basis of availability and analytical convenience and because each of them provided some combination of time, temperature, and confinement that we thought might enhance the beneficial impact of the war pretreatment we were testing. We felt the most important criterion was the ability to bring the pretreated coal quickly to the temperature at which volatiles-producing chemistry is rapid, under conditions that maintain as much as possible of the volatile pretreatment additive in contact with the reacting coal material. Thus, we began by using in situ pyrolysis-field ionization mass spectrometry (Py-FIMS) because of its powerful on-line analysis capability, even though slow heating under high vacuum is not very favorable for maximizing retention of volatile additives during heating up to the $450^{\circ}-500^{\circ} \mathrm{C}$ region. After the Py-FIMS tests, we used atmosphericpressure, slow-heating thermogravimetric analysis (TGA); rapid-heating vacuum TGA; and sealed-ampule pyrolysis because they progressively decreased the chances for premature loss of the moderately volatile additive. 


\section{RELEVANCE TO DOE MISSION}

The mild gasification program at the Morgantown Energy Technology Center (DOE-METC) is directed at recovering condensible hydrocarbons and chars for use as fuel or value-added products under relatively mild temperatures (below $700^{\circ} \mathrm{C}$ ) and pressures (below $50 \mathrm{psi}$ ). SRI's project sought to develop a better understanding of the factors that control the release of volatiles and to develop specific coal pretreatments for maximizing the use of hydrogen indigenous to the coal for volatiles production. This understanding will be useful in tailoring mild gasification processes to match desired volatile and char coproducts. The general results of this project-namely that at heating rates of $\sim 30,000 \mathrm{~K} / \mathrm{s}$ high tar yields are obtained in very short times at relatively low temperatures, and that under these conditions tar yields for even a subbituminous coal approach those for high-volatile bituminous coals-have significant implications for what is in principle achievable under mild gasification conditi'ons.

Greater use of coal for energy and feedstock is desirable in the face of shrinking petroleum reserves. A more correct and more complete picture of coal pyrolysis is necessary if "understanding" is to be useful in directing experimentation toward processes for more efficient conversion of coals to desirable products.

DOE is supporting several efforts to explore different reactors and configurations for mild gasification, such as the fluidized-bed pyrolyzer, the moving-bed pyrolyzer, and the screw reactor. These large-scale (bench or pilot) efforts are supported by fundamental iaboratory studies, many of which are conducted with reactors designed to mimic the behavior of large-scale reactors, with the attendant secondary reactions. These secondary reactions often preclude straightforward interpretation of results. Pyrolysis in a heated grid with cold gas sweep is a laboratory approach that minimizes secondary reactions, but the reaction environment of the coal varies widely with coal rank as the degree of softening and wetting of the wire mesh changes.6,7 Furthermore, measuring the temperature of reacting coals in wire-grid pyrolysis, particularly under high heating rates, is fraught with large uncertainties. ${ }^{8-10}$ Our study complements those other studies because it was designed to focus on the impact of a pretreatment or process variation on primary pyrolysis, relatively free from secondary reactions of the evolved volatiles, under high heating-rate conditions that still permit temperature measurement using infrared imaging and that allow efficient char-tar separation and collection. A significant finding of this study is that, even at temperatures as low as $500^{\circ} \mathrm{C}$, evolution of volatiles can be extremely rapid under high heating rates.

During this project, we collaborated with DOE scientists and other DOE contractors by providing FIMS analysis of the tars produced in their reactors. One such study (involving METC and Advanced Fuel Research) examined the differences resulting from heating rate and was presented ${ }^{11}$ at a symposium convened by the Division of Fuel Chemistry in conjunction with the 
American Chemical Society (ACS) National Meeting in September 1989. A full manuscript on this work is now in preparation. 


\section{WORK PE'RFORMED}

\section{SLOW PYROLYSIS IN FIMS}

When coals are pyrolyzed in the inlet of the FIMS instrument, the volatiles are released in the vacuum and are analyzed without undergoing any more cycles of condensation and evaporation. Thus, this method minimizes secondary reactions of the volatiles (once they are in the vapor phase) and provides a baseline for comparing the nature of tars formed under different pyrolysis conditions. Such a comparison was performed jointly with Advanced Fuel Research (AFR) and METC. The preliminary results of this study were reported at the ACS National Meeting in Miami Beach, September 1989. FIMS analyses of tars obtained by using AFR's rapid pyrolysis entrained-flow reactor (EFR) and METC's slow-heating-rate organic devolatilization reactor (SHRODR) were compared with the results of in situ FIMS pyrolysis of the Upper Freeport, Pittsburgh, and Utah Blind Canyon coals of the Argonne Premium Coal Sample Program (APCSP). In general, the tars formed by using SHRODR have low average molecular weights and narrow molecular weight distributions, compared with the tars from EFR or in situ FIMS. The low molecular weight tars from SHRODR are a result of secondary cracking made possible by the long residence time. SHRODR tars were also low in nitrogen, as reflected in the reduced intensity of the ions at odd masses in the FIMS analyses of these tars. The preprint describing this study 11 is listed under Fublications Resulting from the Project.

During the project we also examined the in situ FIMS pyrolysis of all eight coals from the APCSP. In general, the spectra for the total tars evolved during temperature-programmed pyrolysis appear to be composed of two groups of peaks. First, there is a cluster of prominent peaks in the low molecular weight range (100-200 Daltons) that clearly belong to various homologous series. Second, there is a broad, roughly Gaussian, distribution of peaks spanning the mass range 150-1000 Daltons in which there are no prominent homologous series. The low molecular weight cluster is particularly dominant in the Beulah Zap lignite and the Wyodak subbituminous coal. With increasing coal rank, the prominence of this cluster decreases relative to the broad Gaussian envelope, whose means appears to shift to higher masses with increasing rank.

Within the cluster of phenolic peaks, the relative importance of dihydric phenols decreases with increasing coal rank. The higher-rank coals, particularly the Upper Freeport and the Pocahontas coals, clearly show the growth of lurge PCAH structures. Their presence is less evident in the lower-rank coals, although the presence of the pyrene nucleus was unmistakable 
even in the Utah coal. While some of these trends are known from other studies, FIMS provides an easy means for quantifying them and developing indices that could be used in modeling. A preprint describing these results in more detail ${ }^{12}$ is listed under Publications Resulting from the Project.

\section{MODERATELY FAST PYROLYSIS IN VACUUM TGA}

Pyrolysis in the temperature-programmed inlet of SRI's FI mass spectrometer (Py-FIMS) has the advantage of providing on-line detailed information on the nature and yield of the tars. However, the combination of high vacuum and slow heating rate $\left(5^{\circ} \mathrm{C} / \mathrm{min}\right)$ could mean that little tar additive remains within the coal by the time the $400^{\circ}-500^{\circ} \mathrm{C}$ temperature range of maximurn reactivity is reached. Not surprisingly, therefore, this technique revealed no improvement in tar yield as a result of tar pretreatment, so we decided to use another laboratory technique in which adfitive loss would not be so severe. Vacuum thermogravimetry is similar to Py-FIMS in that the heating is in vacuum and a record is continuously provided of the amount of material that has been volatilized, but it differs in that heating rates as high as about $10^{\circ} \mathrm{C} / \mathrm{s}$ can be achieved by raising a furnace, preheated to $1000^{\circ} \mathrm{C}$, around the quartz envelope containing the sample suspended in a transparent quartz boat. Results obtained after the pretreatment technique was refined are described briefly below. More preliminary results from this series of experiments are listed under Publications Resulting from the Project.

We extended our original tests using unhydrogenated and mildly hydrogenated coal tars for the pretreatment to include the use of more highly hydrogenated coal tars. These tars were obtained by prehydrogenation using a hydrous titania catalyst developed at Sandia National Laboratories for use in hydrogenating pyrolysis tars. The catalyst was obtained through the courtesy of Dr. H. P. Stephens. The tar additive was prehydrogenated by using these active catalysts at $200^{\circ}$ and $300^{\circ} \mathrm{C}$ and 100 psi $\mathrm{H}_{2}$. FIMS analysis of the parent and reduced tars showed that the extent of hydrogenation was slight for the 3- and 4-ring PCAH components but much more substantial for the 5-ring and larger components. For example, the sums of peaks corresponding to the dihydrogenated components of phenanthrene, pyrene, and dibenzpyrenes under the more vigorous hydrogenation conditions were $1.4 \%, 2.1 \%$, and $15.0 \%$, respectively.

The impact of tar loading was determined by comparing the volatiles produced (weight loss) as a function of time and temperature with those produced frum the pyrolysis of the respective blank (i.e., tetrahydrofuran-treated coal). In each case, corrections were made for small losses of moisture from the silica plugs, buoyancy effects, and possible magnetic susceptibility effects by performin for comparison a blank run in which all these factors were essentially identical with those vi the tar-treated run. To simulate the volatility of the loaded tar itself, an 
additional run was made by loading the tar loaded onto charcoal. This run suggested that $90-100 \%$ of the added tar was volatilized by the time the final temperatures of about $450^{\circ} \mathrm{C}$ were reached. The impact of tar treatment was conservatively calculated by assuming that $100 \%$ of the added tar was volatilized.

Shown in Table 1 are the results for the final series of vacuum TGA pyrolyses using a Wyodak, an Illinois No. 6, and a Pittsburgh coal. The final weight losses as a percentage of the coal organic matter are shown in column 3 , and the fractional changes in the volatiles production effected by the tar additive are shown in column 4 . Improvement factors obtained by interpolation (or minor extrapolation) of the observed weight loss in the tar-treated run to correspond to that at the maximum temperature of the blank run are given in column 5. In contrast to previous results obtained in this project ${ }^{13}$ with different pyrolysis techniques using unreduced or less highly reduced tars, the effect of the tar additive in all cases is to increase the net volatiles yield by a factor of 1.1 to 1.3 .

Table 1

EFFECT OF PRETREATMENT WITH HYDROGENATED COAL TAR ON VOLATILES YIELD (VACUUM PYROLYSIS TO $T_{\max }=\sim 450^{\circ} \mathrm{C}$ )

\begin{tabular}{|c|c|c|c|c|}
\hline Coal Run & $\begin{array}{c}T \max \\
\left({ }^{\circ} \mathrm{C}\right) \\
\end{array}$ & $\begin{array}{l}\text { Final Weight Loss } \\
\text { (\% Organic Matter) }\end{array}$ & $\begin{array}{c}\begin{array}{c}\text { Relative } \\
\text { Enhancement }\end{array} \\
\end{array}$ & $\begin{array}{l}\text { Temperature-Adjusted } \\
\text { Enhancement Factor }\end{array}$ \\
\hline \multicolumn{5}{|l|}{ Wyodak ${ }^{a}$} \\
\hline Blank & 452 & 28.9 & 1.00 & \\
\hline $\mathrm{H}$-tar treated & 448 & 35.6 & 1.23 & \\
\hline $\mathrm{H}$-tar treated & 441 & 31.6 & 1.09 & 1.31 \\
\hline \multicolumn{5}{|l|}{ Illinois No. $6^{a}$} \\
\hline Blank & 443 & 27.2 & 1.00 & \\
\hline $\mathrm{H}$-tar treated & 456 & 34.3 & 1.26 & \\
\hline $\mathrm{H}$-tar treated & 434 & 28.2 & 1.02 & 1.12 \\
\hline \multicolumn{5}{|l|}{ Pittsburgha } \\
\hline Blank & 441 & 23.7 & 1.00 & \\
\hline $\mathrm{H}$-tar treated & 444 & 28.9 & 1.26 & $1.20-1.26$ \\
\hline
\end{tabular}


These results suggest the potential for even great beneficial impacts from other conditions that would further improve the chances for a substantial portion of a moderately volatile tar additive to remain within the coal through the critical reaction period. In particular, we anticipated that during laser pyrolysis, when the heating rate was 3 orders of magnitude faster and the pressure was $1 \mathrm{~atm}$, early loss of the tar additive would be minimized. Nevertheless, the yield enhancements eventually obtained with laser pyrolysis or similarly pretreated coals were no greater and sometimes substantially less than those shown in Table 1.

\section{VERY RAPID LASER-HEATED PYROLYSIS}

Among the pyrolysis approaches used in this project, laser pyrolysis represents the opposite end of the heating-rate spectrum from pyrolysis in the source of a field ionization mass spectrometer (Py-FIMS). We developed an apparatus for pyrolyzing an entrained flow of coal particles with a continuous wave (CW) infrared laser that would bring coals loaded with volatile "promoters" to reaction temperature in an unconfined environment with minimal loss of promoter. Brief accounts of this technique are listed in Publications Resulting from the Project. A more detailed description is presented here.

The laser-pyrolysis appruach produces in-depth heating of the coal, providing rapid heat-up to a steady-state :rolysis temperature, which is naturally determined by the balance between radiative input to the particle and the sum of convective and radiative heat losses to thie cold gas. The advantages of this pyrolysis mode are listed below.

- It provides very rapid heat-up to the steady-state temperature and thus is a close approximation of the idealized temperature-jump experiment.

- The initially produced volatiles are evolved into a cold-gas atmosphere so that secondary reactions obscuring the nature of the original volatiles are minimized.

- The flow system, in which thousands of $50-\mu \mathrm{m}$ particles are pyrolyzed per second, allows the collection of tens of milligrams of tar and other products for later analysis, something not possible with a single-particle approach.

The difficulty in this approach is the need to provide constant flow rates and particle loadings, as well as laser illumination that is uniform in time and space and reasonably omnidirectional. Furthermore, because even a narrow physical and aerodynamic particle-size distribution inevitably has some range of particle velocities, residence times, and steady-state temperatures, the need for rapid pyrometric temperature measurement on an individual particle basis is increased. 


\section{Laser-pyrolysis Apparatus}

A schematic diagram of the laser-pyrolysis apparatus is shown in Figure 2. Coals obtained from grinding and wet-sieving under nitrogen (typically the 270/230-mesh fraction; nominal diameter range $53-63 \mu \mathrm{m}$ ) are loaded into the hopper of a rotating-disk dust feeder that feeds a fluidized bed, using argon as the entrainment gas. This bed in turn feeds the inlet of the 3-mm-i.d. ejector tube, the outlet of which is just downstream of an aluminum honeycomb flow straightener and 3-5 mm upstream of the region where the IR laser beam crosses the axis of particle flow. Condensible volatiles either are ejected from the pyrolyzing coal particles as an aerosol or quickly form one when they encounter the cold argon stream. Several millimeters downstream of the heated zone, the tar-aerosol and char-particle stream enters a collector with an 8-mm i.d. and a conical interior that smoothly decreases to $3 \mathrm{~mm}$. The flow then passes through a miniature cyclone designed to collect particles larger than $\sim 10 \mu \mathrm{m}$. The tar aerosol with particles (typically 0.2-0.3 $\mu \mathrm{m}$ in diameter) and any other small particles pass through the cyclone and are collected on one of a pair of filters in a parallel-flow filter arrangement. The char-tar separation is very good; microscopic examination shows that the cake on the filter consists of tawny yellow tar aerosol particles essentially free of black coal or char particles of any size. The cyclone contains all the char, with small amounts of tar aerosol attached to some of the char particles, evidently as a result of collisions within the cyclone. Because the aerosol particles were $\sim 0.3 \mu \mathrm{m}$, compared with $\sim 50$ $\mu \mathrm{m}$ char particles, the mass fraction of tar contaminating the char was very low: typically less than $5 \%$. This tar contamination could easily be removed from the char by a quick tetrahydrofuran (THF) wash. We removed the tar contamination before char analysis. However, no correction was typically made for the percentage yields of tar. Thus the tar yields listed will actually be low by 0 to 5 percentage points.

The beam from a Coherent Model $41 \mathrm{CW} \mathrm{CO}_{2}$ laser is passed through an $8-\mathrm{mm}$ orifice in a graphite disk to remove the fringes and is then directed to the cell by two flat and one slighily concave (20-m radius of curvature) copper mirrors. The beam emerging from the laser has a Gaussian profile, which is not suitable for our purpose. To convert the Gaussian profile into a flat profile, we use a channel integrator as shown in Figure 3. The laser beam is focused through a point using a 1-in. focal length zinc selenide lens and allowed to expand into a channel integrator consisting of polished aluminum plates bolted together to form a channel having a $6.5-\mathrm{mm}$ square opening. The divergent radiation that exits this channel is then imaged with a second lens through the $\mathrm{KCl}$ window in the pyrolysis cell and onto the axis of particle flow. The "beam" (which diverges after passing through the particle stream) is reimaged back on the flow axis by a concave copper mirror on the back side of the cell to minimize "jetting" of the particles caused by heating on only one side. Figure 4 is a close-up view of the cell that shows how the channel-integrator output 


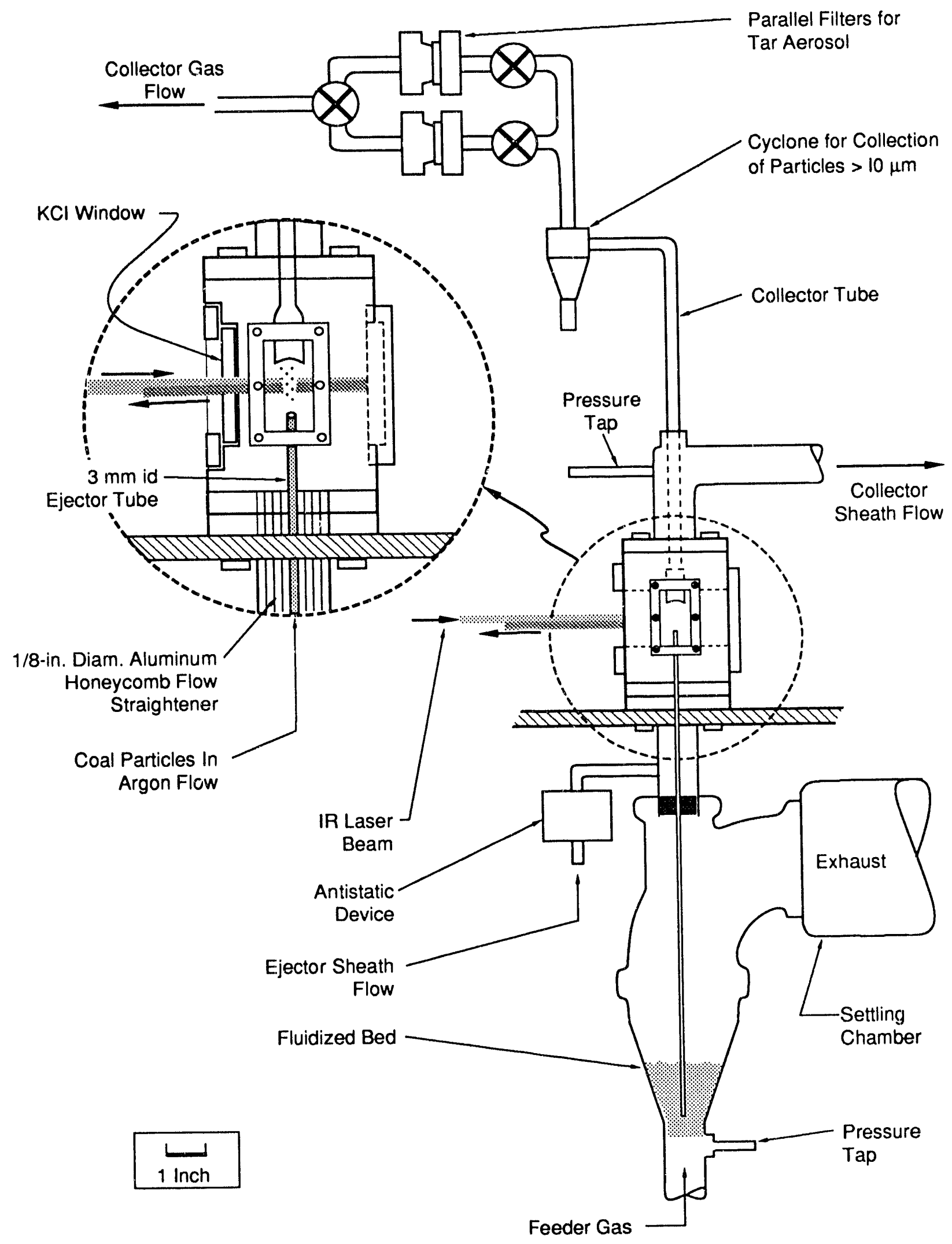

RM-4159-2

Figure 2. Schematic of entrained-flow laser pyrolysis apparatus. 


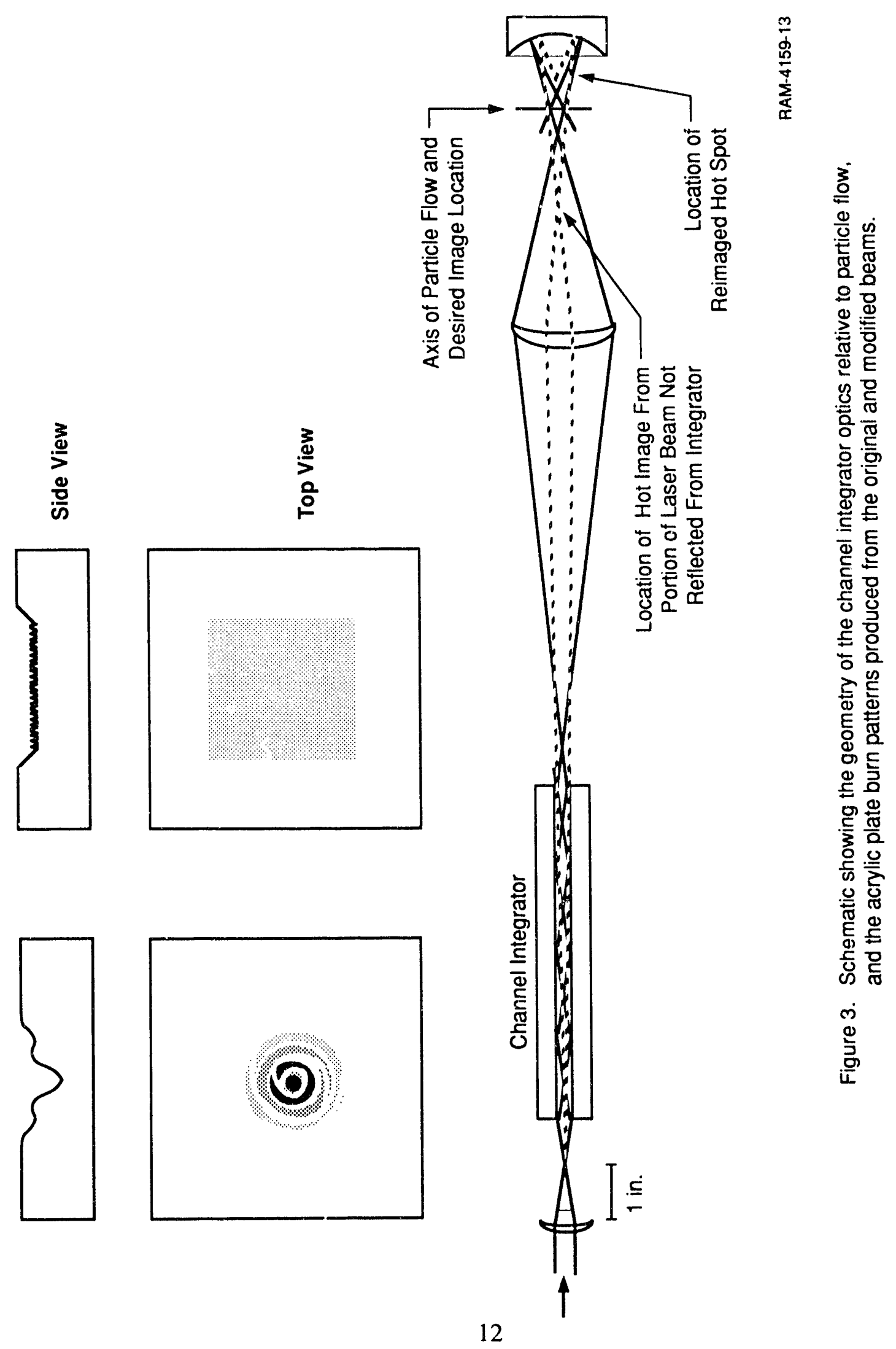




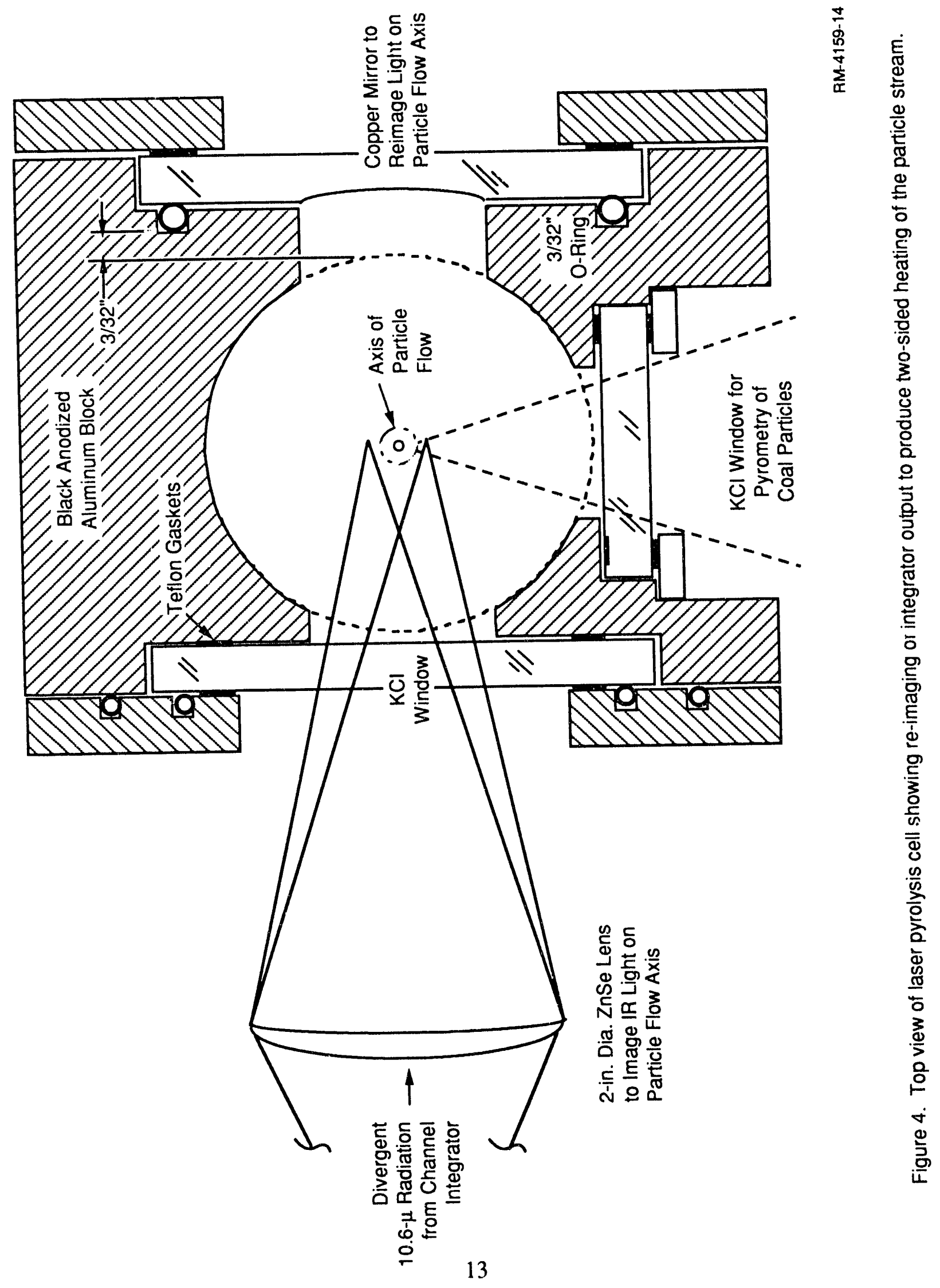




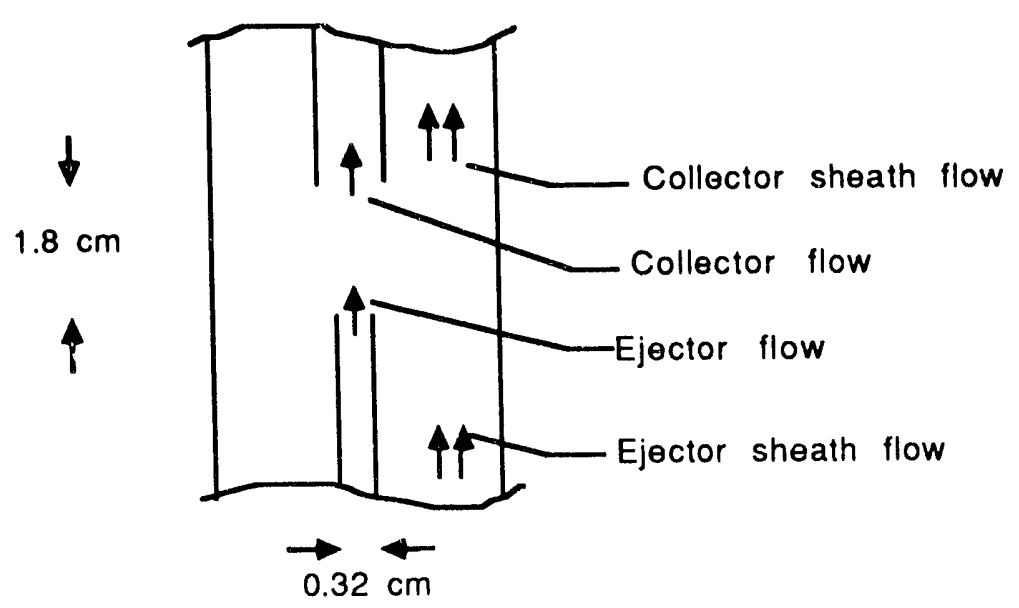

Figure 5. Schematic of ejector-collector sheath geometry.

Table 2

TYPICAL CONDITIONS FOR ENTRAINED-FLOW LASER PYROLYSIS

Coal particle size

Ejector-collector distance

Laser image size

Power
$250 / 270$ mesh (nominally $53-63 \mu \mathrm{m}$ )

$1.5 \mathrm{~cm}$

$0.5 \mathrm{~cm} \times 0.5 \mathrm{~cm}, 0.4 \mathrm{~cm}$ above ejector $\sim 200 \mathrm{~W} / \mathrm{cm}^{2}$ (one way)

Average Carrier Space Velocities

(volumetric flow rate/cross-section area)

Ejector sheath

Collector Sheath

Collector

Ejector

Estimated settling velocity
$14.0 \mathrm{~cm} / \mathrm{s}$

$14.0 \mathrm{~cm} / \mathrm{s}$

$14.2 \mathrm{~cm} / \mathrm{s}$

Ranging from 10.4 to $20.6 \mathrm{~cm} / \mathrm{s}$ at

0.020 to 0.040 in. water vacuum

$\sim 10 \mathrm{~cm} / \mathrm{s}\left(58-\mu \mathrm{m}\right.$ sphere, $\left.\rho=1.3 \mathrm{~g} / \mathrm{cm}^{3}\right)$ 
is manipulated to provide two-sided heaing. The radiation not absorbed by the second pass diverges as it exits through the $\mathrm{KCl}$ window and is absorbed by a graphite beam block.

\section{Characterization of Velocity, Particle Size, and Temperature}

Gas Velocity. The gas velocity is readily determined by measuring the frame-to-frame displacement of the clouds or "packets" of smoke (tar aerosol) that are rapidly evolved when the particles are heated to $700^{\circ} \mathrm{C}$ or above. Figure 5 shows a schematic of the various flow streams in the ejector-collector region, and Table 2 lists typical conditions for a pyrolysis run.

Because the tar aerosol particles are $0.2-0.3 \mu \mathrm{m}$ in diameter, the aerosol travels essentially at the carrier gas velocity once it has left the boundary layer of the particle. Viewed under scattered light with close-up high-resolution visible-light video, the aerosol appears as a "packet" of smoke streaming ahead of the particles, as shown in Figure 6. The distance traveled between successive frames of the video ( $33 \mathrm{~ms}$ apart) provides a direct measure of the gas velocity.

The smoke packets in Figure 6 have an aspect ratio greater than 1.0 because of the difference between gas and particle velocities and because of "streaking" while the video image is accumulated. In the example shown in Figure 6 (and other video images from the same run), the observed aerosol cloud velocities (laser on) within the region accepted by the collector ranged from 13.1 to $14.4 \mathrm{~cm} / \mathrm{s}$, compared with the nominal space velocities of $14.0-14.2$ set by the volumetric flow. The velocities observed were slightly higher close to the collector axis, and measured values ranged down to $11 \mathrm{~cm} / \mathrm{s}$ for the occasional smoke packets observed outside the periphery of the collector. This observation is consistent with the parabolic pattern of gas velocity expected for flow in a cylindrical tube. With the laser off, a slight compression of the particle-flow streamlines was observed as the flow entered the collector, as is also consistent with the slightly higher space velocity set for the collector (Table 2 ).

The limited increase in flow $(\leq 3 \%)$ with the laser on means that the volumetric expansion and the bulk temperature increase of the argon carrier are similarly limited. In this case, the temperature increase of the carrier stream was $\leq 50^{\circ} \mathrm{C}$. The degree of carrier heating depends on the particle density; bulk gas heating of $\leq 100^{\circ} \mathrm{C}$ is consistent with the calculated convective heat loss from $\sim 50-\mu \mathrm{m}$ particles, the heat capacity of the "column" of argon carrier flowing past each particle, and a particle density of less than 10 particles in the laser-heated region at any one time.

Particle Velocity. The particle velocity, as distinct from the carrier gas velocity, is readily determined from the fast line-scan mode video record obtained with the imaging radiometer. This record was obtained using an Inframetrics Model 600 IR Imaging Radiometer. This instrument uses a single liquid-nitrogen-cooled $\mathrm{HgCdTe}$ detector filtered to accept light from 7 to $12 \mu \mathrm{m}$ 


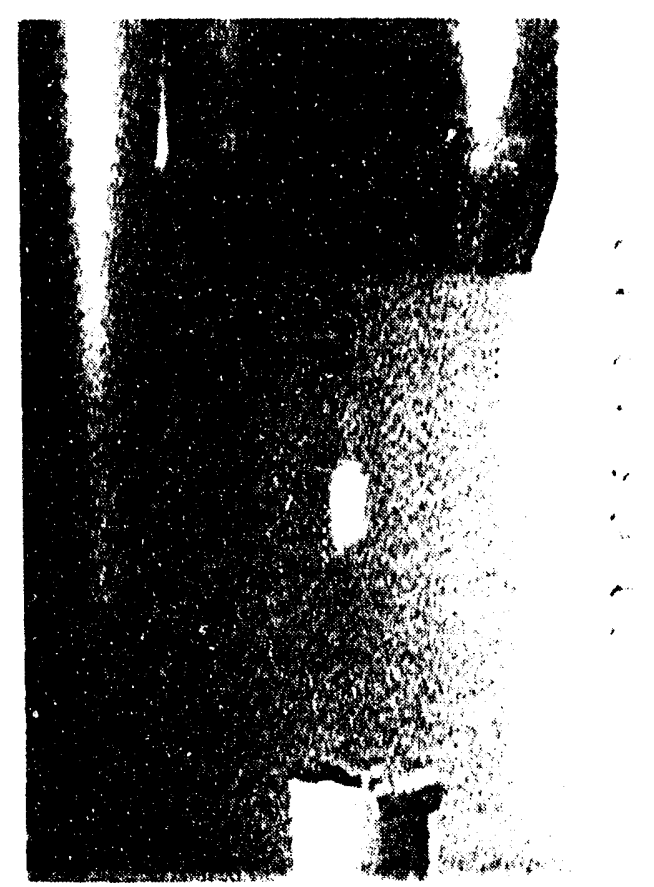

(a)

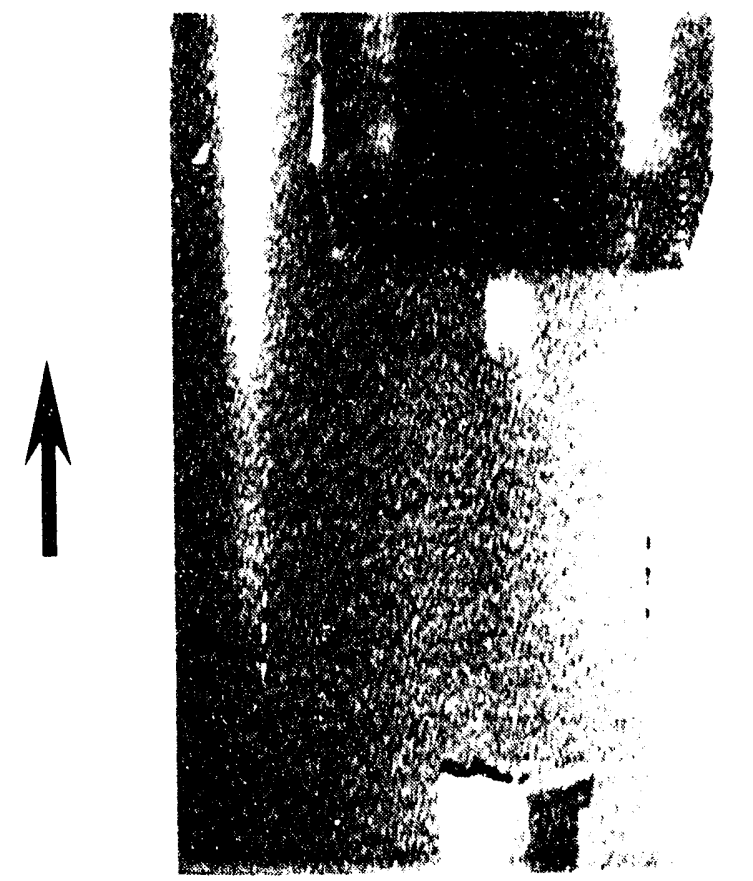

(b)

RP. $4159 \cdot 16$

Figure 6. Photographs showing frame-to-frame displacement of the tar aerosol clouds ejected from pyrolyzing coal particles.

(except for $10-11 \mu \mathrm{m}$, where scattered laser light is blocked by a notch filter). The use of this instrument to measure particle temperature (via measurement of radiance) is discussed in the next section; here we are concerned only with the measurement of particle velocity.

In normal operation, the Model $6(0)$ scans horizontally across the imaged area at $8 \mathrm{kHz}$, while the vertical galvanometer is moved to produce a $1(0)$-line field every $16 \mathrm{~ms}$. Two successive fields are interlaced to generate a 200 )-active-line image every $33 \mathrm{~ms}$. (Thus this instrument differs from a normal charge-coupled-device based video camera because here the radiances of $500 \times 200$ individual fields of view are sequentially sampled for $\sim 0.3 \mu$ s each.) In the fast line-scan mode, the vertical galvanometer is turned off and the detector is swept repeatedly back and forth across the same line. This arrangement, shown schematically in Figure 7, effectively provides a viewing 


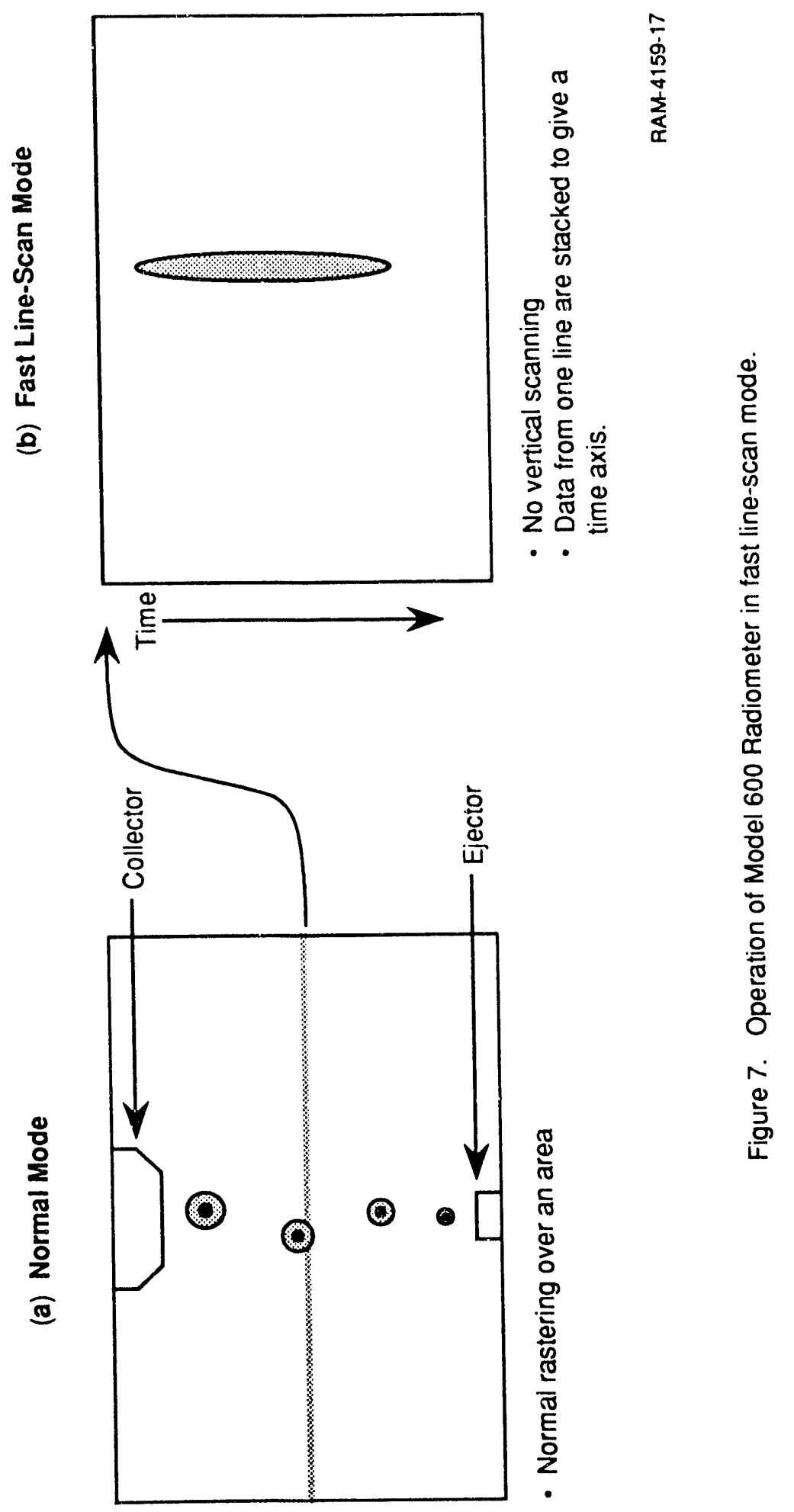


slit that is scanned at $8 \mathrm{kHz}$, which is fast relative to the time required for a particle moving at $\sim 10 \mathrm{~cm} / \mathrm{s}$ to pass the slit. The image produced is a vertically oriented oval, and the slower the particle is moving, the longer the oval. Because the time required for a particle to pass this slit is determined by the height of the slit and the diameter and velocity of the particle, the velocities of individual particles of different apparent radius are obtained by measuring the length of the particle images produced in the fast line-scan mode and the particle-size distribution of the collected char.

When the nominal space velocity (based on the mass flow rates of the inlet system) is $14 \mathrm{~cm} / \mathrm{s}$, the particle velocity is typically found to range from 5 to $9 \mathrm{~cm} / \mathrm{s}$. (This range is larger than we believe actually occurs. It results from taking \pm 1 standard deviations for both the measured streak length and the measured char particle-size distribution, and combining in a way that gives the largest range in determined velocities.)

Particle Size. Because heat transfer considerations dictate that larger particles will be heated to higher steady-state temperatures, measurement of the particle size distribution of the coal feed and the recovered char is an iniegral part of the determination of particle temperature distribution. The relationship between particle size and steady state temperature can easily be seen from the fact that at particle temperatures $\left(\mathrm{T}_{\mathrm{g}}\right)$ below $1000^{\circ} \mathrm{C}$, in $1 \mathrm{~atm}$ of a cool gas, the main heat loss will be convective. The steady state temperature is then essentially determined to be the temperature at which radiative input is balanced by convective heat loss.

$$
\text { Radiative input: } \alpha D^{2} \quad \text { Convective heat loss: } \alpha \quad D\left(T_{p}-T_{g}\right)
$$

Equating these two proportionalities,

$$
\left(T_{p}-T_{g}\right)=\Delta T \quad \alpha \quad D^{2} / D=D
$$

The particle-size distributions were determined from photomicrographs of the feed and the recovered char made by using a LECO 2001 image analyzer. Figure 8 shows the particle size distribution for an Illinois No. 6 feed coal (250/270 mesh, nominal mesh opening range, 53-63 $\mu \mathrm{m}$ ) recovered from a cold-flow (laser off) experiment and for the char sample recovered from pyrolysis of the same coal immediately after the cold-flow run. This figure shows the normalized number of particles per frame falling in the various diameter ranges.

Figure 8 shows that the particles which swell to final char diameters of $75-100 \mu \mathrm{m}$ come primarily from the 55- to $70-\mu \mathrm{m}$-diameter portion of the cold-flow population; laser heating has "cut out" the larger part of the original distribution (particles 60-70 $\mu \mathrm{m}$ in diameter) and displaced it 


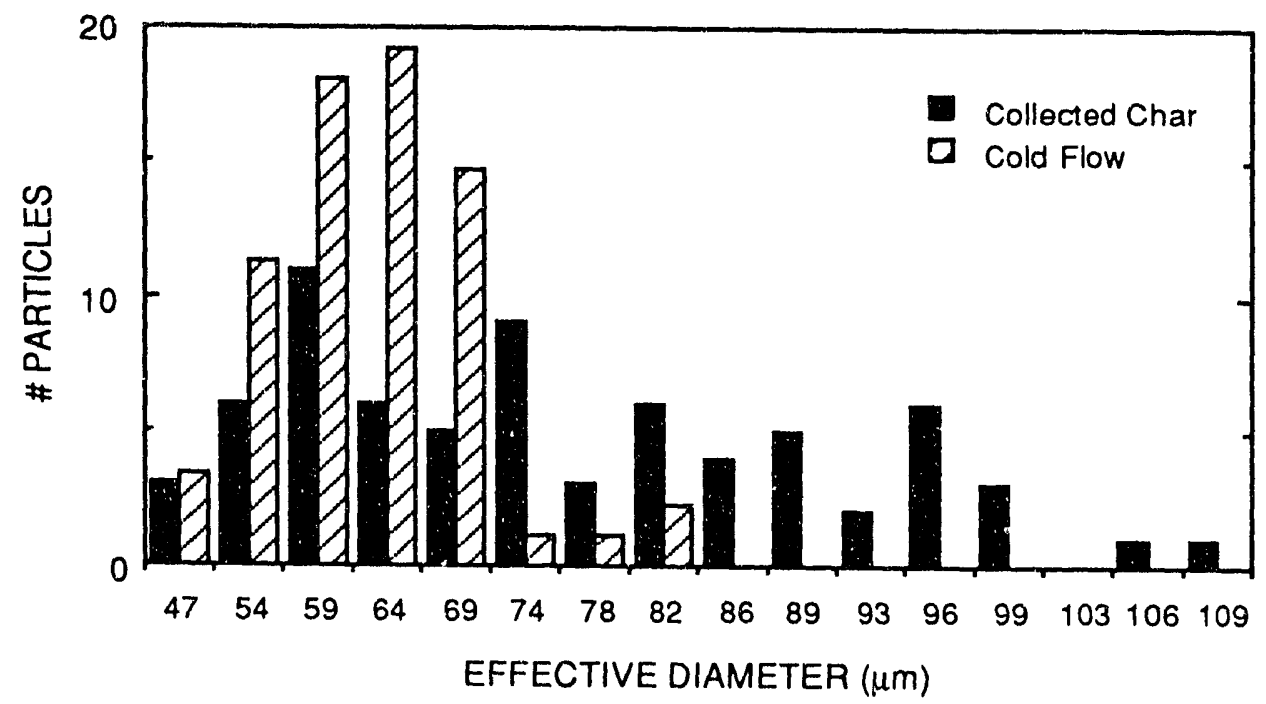

RAM-4159-12

Figure 8. Particle size distribution of coal particles recovered from a cold-flow experiment and cha- particles recovered from laser pyrolysis.

to a higher diameter. In other words, the particles that heated quickly and swelled most were those originally in the high end of the particle-size range.

\section{Particie Temperature Measurement}

Accurate temperature measurement is the key to obtaining reliable information from a hotwall, cold-gas pyrolysis technique. In contrast to a hot-wall, hot-gas pyrolysis approach, in which all coal particles quickly approach the temperature of the gaseous surroundings (which can be straightforwardly measured with thermocouples), pyrolysis in a cold gas necessitates a pyrometric temperature measurement. Furthermore, a distribution of coal particle sizes inevitably results in a distribution of final temperatures. At temperatures above those at which the pyrolyzing coal particles become visibly incandescent, a rough measure can be obtained by using a disappearing filament pyrometer. However, this technique is limited to temperatures of $700^{\circ} \mathrm{C}$ or greater, and it tends to provide a measure of the hottest particles and gi $\%$ s no quantitative information about temperature distribution. Accordingly, after the initial laser-pyrolysis experiments in which we had used a disappearing filament pyrometer, we used close-up infrared video imaging to determine particle temperatures and temperature distributions. We chose this approach because it simul- 
taneously provides a video record covering he entire laser-heated region and a measure of number density and spatial, velocity, and temperature distribution of a set of moving particles. Furthermore, an imaging radiometer was available at SRI.

The use of the Model 600 Imaging Radiometer for temperature measurement of micrometer-sized objects is not straightforward, and various aspects of these measurements are discussed in some detail below in the section entitled Issues in Particle Temperature Measurement. In this section, we describe the temperature measurer ient only in enough detail to make the description of the results comprehensible. In short, the imaging radiometer measures the light emitted by a target over a single wavelength range and thus provides a temperature via its measurement of total radiance. To obtain the temperature of the particle from total radiance, we must know the emissivity and the size of the particle. Recent measurements by Fletcher and coworkers show that the spectral emissivity of coal particles heated to various temperatures generally falls between 0.87 and 0.98 (and is rather flat) at wavelengths between 6 and $13 \mu \mathrm{m} ;{ }^{14,15}$ therefore, we chose the 7 - to $12-\mu \mathrm{m}$ region for temperature measurement (except for the region around the $10.6-\mu \mathrm{m}$ wavelength of the $\mathrm{CO}_{2}$ laser, where a narrow-band filter is used to remove scattered laser light).

When the particle is large enough to completely fill the area imaged onto a single pixel, the emitting surface area is automatically defined by the optics and the object size represented by a pixel; thus, an absolute temperature measurement then ricquires only knowledge of the object emissivity. In this case, $60-\mu \mathrm{m}$ coal particles do not quite meet this size criterion. With available infrared telephoto and close-up lenses, the imaged area is about $0.8 \times 1.0 \mathrm{~cm}$ and an individual pixel in the video image is assigned intensity collected from an area $94 \times 94 \mu \mathrm{m}$, somewhat larger than the $58-\mu \mathrm{m}$ average diameter of the starting coal particles. Therefore, absolute temperature measurement requires that an independent measure of particle size be combined with the temperature output of the imaging radiometer, together with adjustment factors for particle sizes smaller than $94 \mu \mathrm{m}$.

We used the particle size analysis discussed above to determine appropriate adjustment factors in two ways. The first adjustment method was based purely on geometric factors and a knowledge of the time-response behavior of the $\mathrm{HgCdTe}$ detector system. The second method was an empirical approach in which a graphite block of known temperature and emissivity was viewed through masked holes designed to mimic the particle-size range of interest here. Both of these methods are discussed in detail below, under the heading Issues in Particle Temperature Measurement. The two different methods gave very similar temperature distributions, and we 
consider the results as reliable as single-color measurements could be under these circumstances (i.e., $\pm 75^{\circ} \mathrm{C}$ ). Inframetrics, Inc., now makes a two-color version of its imaging radiometer that would be ideal for these purposes; however, this instrument costs $\$ 120,000$ and was not available to us.

When the raw measured maximum temperatures and the measured particle-size distributions are combined (larger particles are heated to higher temperatures), the distributions of steady-state particle temperatures are obtained. One such distribution is shown in Figure 9, together with the particle-size distribution for the feed coal, the material collected in a cold-flow experiment, and the char recovered after laser pyrolysis, plotted in terms of "effective" diameter $\left(2[\operatorname{are} a / \pi]^{1 / 2}\right)$ on a log-normal plot.

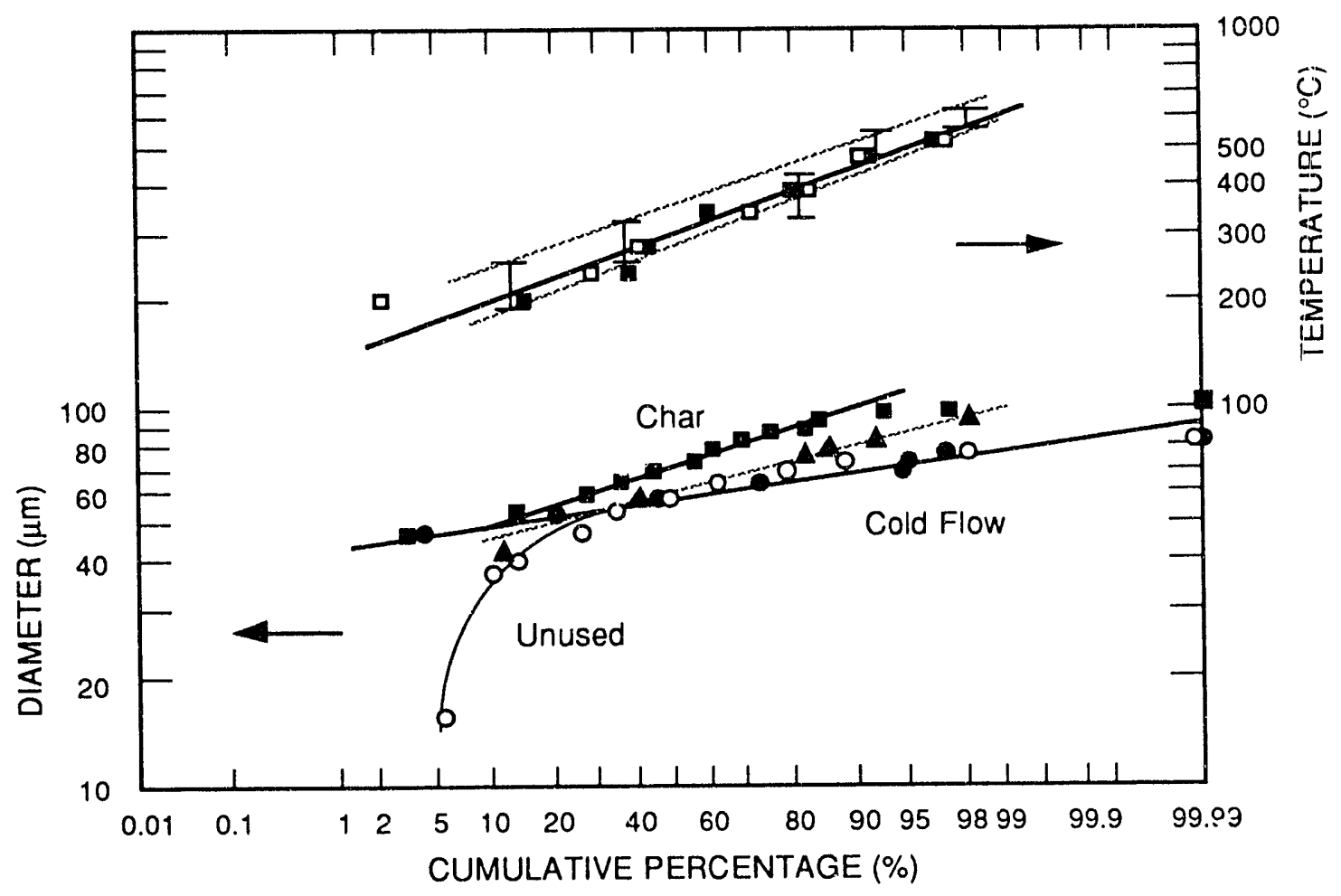

RM-4159-7A

Figure 9. Particle size distribution of coal, coal entrained under cold-flow conditions, and coal char, compared with the temperature distribution measured during pyrolysis. 
The feed ("unused" coal), and the cold-flow material in Figure 9 are very similar, except that the unused material, which was charged to the dust feeder before the series of runs from which the current data were obtained, contains $\sim 20 \%$ (by number) material in the $15-$ to $45-\mu \mathrm{m}$ range. Under the flow conditions used during pyrolysis, essentially all these fines were carried out of the system in the first test run with that coal sample and were thereafter not a part of the feed. In contrast to the difference between the raw feed and the cold-flow material at the low-particle-size end, Figure 8 shows that the coal char has a distribution beginning at the same lower size limit as that of the cold-flow material but extending (at $98 \%$ cumulative undersize) to $100 \mu \mathrm{m}$ rather than the $75 \mu \mathrm{m}$ of the cold-flow material. The char particle-size distribution and the measured particle temperature distribution in Figure 9 have very similar slopes on the log-normal plot (that is, similar dispersions). This result is exactly what was expected from the proportionality between particle size and steady-state temperature predicted by heat transfer considerations: Over a given percentile range, the percentage of change in observed $\Delta \mathrm{T}$ (particle temperature minus gas temperature) should be the same as the percentage of change in char particle size.

When the temperature is determined by the method described above and as a function of position along the axis of particle flow, the temperature profile of the particle stream is obtained. One such temperature profile is shown in Figure 10, which illustrates that the entrained-flow laserpyrolysis technique results in a fair approximation of the idealized temperature jump experiment, certainly much closer to that ideal than can be achieved with pulsed laser pyrolysis.

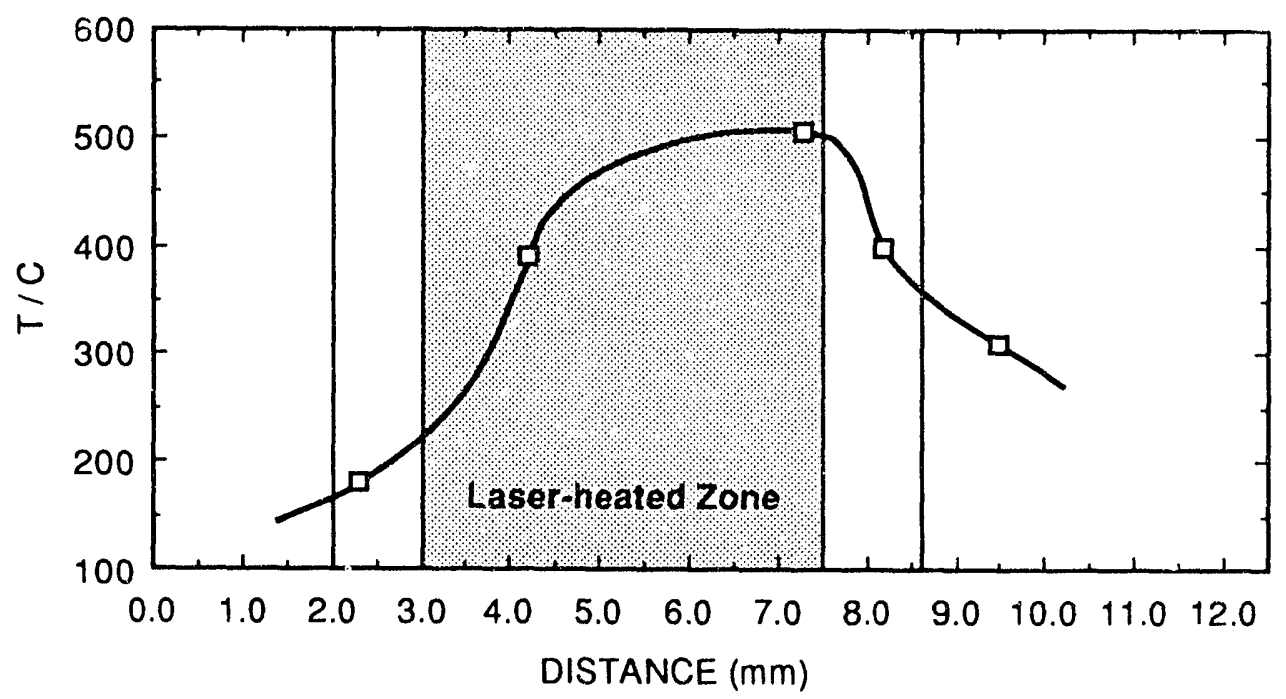

RAM-4159-19

Figure 10. Temperature profile of the particles in the laser pyrolysis cell 


\section{Effect of Temperature on Tar Yield and Character}

Tar Yield. Figure 11 shows the effect of particle temperature on the tar yield. The values plotted on the ordinate are based on the weight of the separately collected tar and char and are corrected for the tar added in the pretreatment, assuming that $100 \%$ of that additive is released in the pyrolysis and recovered. Because the ash balances could not be used to determine exact gas yields, owing to density selection during entrainment, an upper limit to the gas yields was derived on the basis of literature data of Solomon 16,17 and of Friehaut. ${ }^{18}$ The gas yields for the high volatile bituminous coals (Pittsburgh and Illinois No. 6) were assumed to be equal to those observed by Freihaut 18 for a Pittsburgh coal under his "cool gas" entrained-flow pyrolysis conditions; they rise from about $15 \%$ of the total volatiles al particle (and gas) temperatures of $\sim 650^{\circ} \mathrm{C}$, where the tar yield is $\sim 10 \%$, to $30 \%$ of total volatiles ai a final gas temperature of $850^{\circ} \mathrm{C}$,

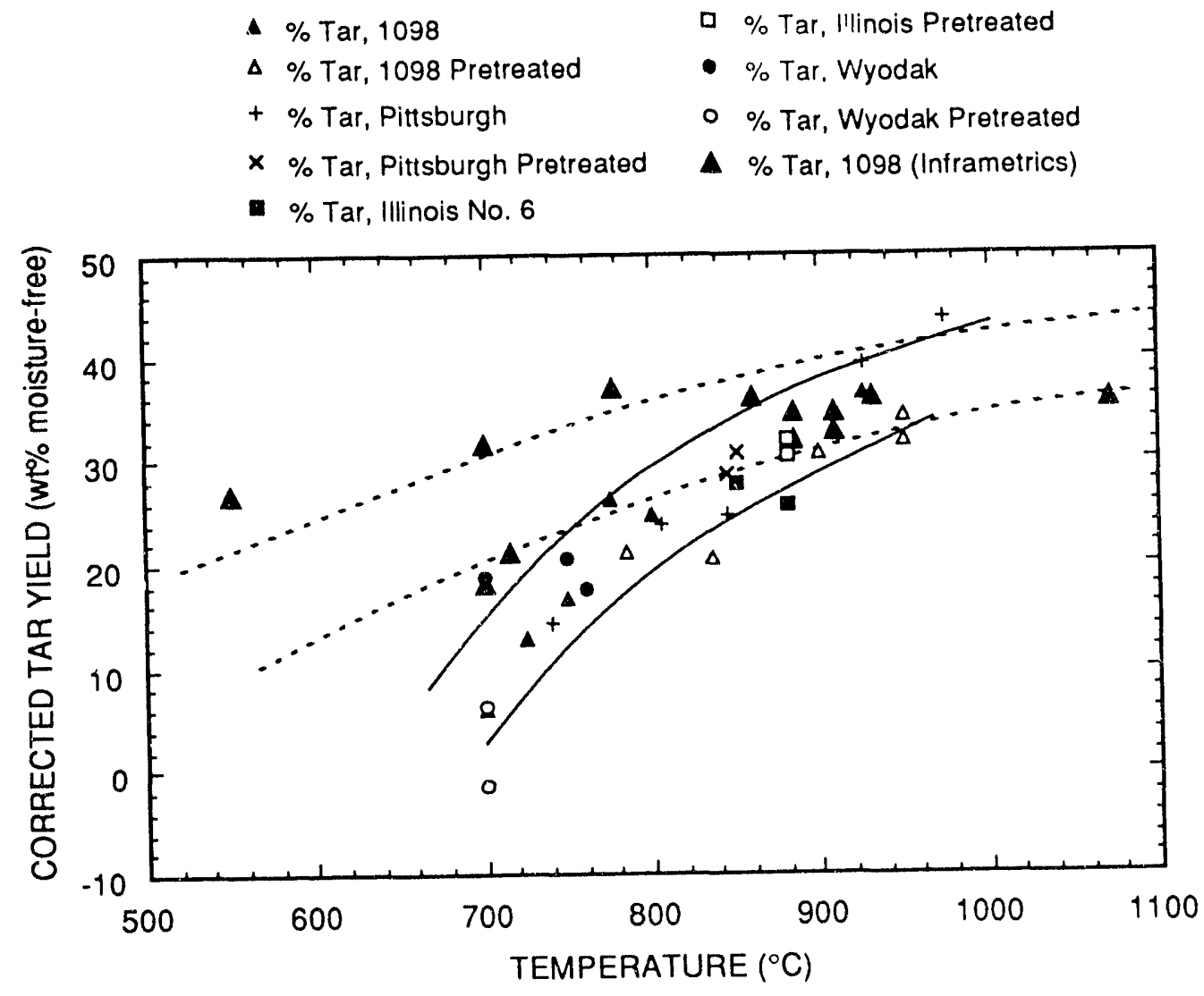

RAM-4159-20

Figure 11. Effect of particle temperature on moisture-free tar yield from raw and pretreated coals. 
where the tar yield is $\sim 35 \%$. For Wyodak the gas yields were taken to be $33 \%$ higher, as is consistent with the relative gas yields reported by Solomon for Pittsburgh and Wyodak coals. ${ }^{19}$ The gas yields estimated in this manner represent conservative values for gas yields under the laser-pyrolysis conditions, because under Freihaut's conditions ${ }^{18}$ the final gas and particle temperatures are essentially the same, whereas under our laser-pyrolysis conditions the final gas temperature is at least $400^{\circ} \mathrm{C}$ below the final particle temperature.

There are two sets of data in Figure 11. The first is a set for pretreated and untreated coals, in which the temperature was determined with a disappearing filament pyrometer (for about the 90th percentile in particle temperature). This set of data was obtained before the use of the channel integrator was fully optimized to relocate the hot spot resulting from laser light that is right on the beam axis and therefore passes directly through the channel integrator without reflecting off the wails. Thus, the fraction of the particles heated to temperatures significantly below the hottest particles was greater than in later runs. The second set of data was obtained with temperature determination via the imaging radiometer and after the hot spot had been moved out of the way of the coal stream. Thus, the temperature spread in this second set of data should be significantly less than that in the first. For this reason, we expected to see higher tar yields at the same nominal temperature in the second series of runs. This expectation appears to have been fulfilled at the lower temperatures, where the tar yields (Illinois No. 6 coal) are still $\sim 20 \%$ at a 95th percentile particle temperature of $550^{\circ} \mathrm{C}$. However, inasmuch as the tar yields seem to be approaching an asymptote of $40-45 \%$, this difference diminishes at higher temperatures.

The scatter seen in the plot is most likely a result of errors in determining the range of particle temperatures. If a band is drawn around the first set of data and all the scatter is attributed to temperature errors, we see that it amounts to only about $\pm 40^{\circ} \mathrm{C}$. In fact, the narrowness of this band is surprising, considering that the plot includes four different coals, both loaded and unloaded. Within the scatter of the data, there is no clear increase in tar yield from the pretreated coals. This result is disappointing but not inconsistent with our observations, using several other pyrolysis techniques, that the increase in tar yields (after correcting for the tar added in the pretreatment) ranged from 0 to about $20 \%$ (i.e., 0 to $\sim 7 \%$ on a moisture- and ash-free (maf) basis.

The observation of similar tar yields from Wyodak and Pittsburgh coals is rather unexpected in view of the widely differing yields reported under slow-heating TGA conditions by Solomon and coworkers ${ }^{17}$ for the same Argonne Sample Bank coals (13\% and $24 \%$ for Wyodak and Pittsburgh, respectively). We may be seeing a substantially greater heating rate dependence of tar yield for the low-rank coal (and therefore a greater benefit from very rapid heating), owing 
to Wyodak's greater tendency to undergo low-temperature retrograde reactions. This variation is consistent with (but appears to be more pronounced than) data reported in the literature. ${ }^{20}$

Table 3 elaborates on these technique and coal comparisons, with some tar and total volatiles yields taken from the literature, and with some averaged laser-pyrolysis tar yields from the present work. As indicated above, the tar yields from Pittsburgh coals are similar in the three entrained-flow techniques though somewhat higher in the laser-pyrolysis technique than in Freihaut's "cool-gas" EFR. The 42\% laser-pyrolysis tar yield at the highest temperature of the present work $\left(\sim 1000^{\circ} \mathrm{C}\right)$ is quite similar to the $40 \%$ total organic volatiles yield obtained at $1100^{\circ} \mathrm{C}$ in Solomon's hot-gas EFR, 19 but much higher than the actual tar yield observed at that temperature. The most striking observation is that the laser-pyrolysis tar yield data for the Wyodak coal, although less extensive than the data for the Illinois No. 6 coals, show the tar yields for the subbituminous coal to be not substantially less than those of the three bituminous coals. This similarity is particularly striking when comparison is made with the 2.6-fold increase in tar yield observed ${ }^{17}$ on going from Wyodak to Pittsburgh coal under normal TGA conditions $\left(10^{\circ} \mathrm{C} / \mathrm{min}\right)$. It is interesting to note that, upon demineralization, the TGA tar yield for the Wyodak coal rises almost to the $23 \%$ level attained for the Pittsburgh coal. As Solomon and coworkers point out, this difference after demineralization is evidently because the mineral matter is active in some way in promoting retrograde reactions. The high tar yields obtained for raw Wyodak under laser-pyrolysis conditions raise the interesting question whether demineralization would raise the laser-pyrolysis Wyodak tar yield still further, possibly making it higher than the Pittsburgh tar yield.

Tar Character. The laser-pyrolysis tars generated from all four coals were collected entirely in the form of tawny yellow aerosol spheres (solid at room temperature) that darkened over several hours when exposed to air at room temperature. Py-FIMS was used to analyze a selection of the tars. Perhaps the most interesting general result of these analyses is that a substantial fraction of some of the tars was not volatile under these analysis conditions. The volatilities during FIMS analysis were uniformly high for the Wyodak (90\%) and Pittsburgh coals $(82-92 \%)$ but substantially lower $(57-77 \%)$ for the two Illinois No. 6 coals. Furthermore, a higher pyrolysis temperature resulted in a tar of lower volatility for the PSOC 1098 Illinois No. 6 coal but not for the Pittsburgh Argonne coal.

Generally, any fossil fuel material that has been distilled is completely $(>95 \%)$ volatile under FIMS analysis conditions $\left(\sim 50 \mu \mathrm{g}\right.$ heated to $500^{\circ} \mathrm{C}$ at $3^{\circ} \mathrm{C} / \mathrm{min}$ at a pressure of $<10^{-6}$ torr). Thus, either a substantial part of the Illinois No. 6 tar is ejected as an aerosol without ever being in the vapor phase, or it retrogresses so rapidly that substantial crosslinking occurs in the milliseconds before it cools. We consider the former much more likely, because the FIMS 
Table 3

\section{COMPARISON OF LASER-PYROLYSIS TAR YIELDS WITH THOSE OBTAINED FROM OTHER ENTRAINED-FLOW PYROLYSIS TECHNIQUES}

\begin{tabular}{|c|c|c|c|c|}
\hline Technlque/Investigator & Coal & $\begin{array}{c}\text { Twall } \\
\left({ }^{\circ} \mathrm{C}\right) \\
\end{array}$ & $\begin{array}{c}\text { Tgas } \\
\left({ }^{\circ} \mathrm{C}\right) \\
\end{array}$ & $\begin{array}{c}\text { Tar Yield } \\
\% \text { maf } \\
\end{array}$ \\
\hline \multirow[t]{5}{*}{ "Cool Gas" EFR, Freihaut ${ }^{b}$} & Pittsburgh & 1240 & 1050 & $33^{c}$ \\
\hline & (PSOC 1451) & 1070 & 900 & 26 \\
\hline & & 939 & 795 & 20 \\
\hline & & 825 & 660 & 14 \\
\hline & & 668 & 500 & 4 \\
\hline \multirow[t]{3}{*}{ "Hot-Gas" EFR, Solomond } & $\begin{array}{l}\text { Pittsburgh } \\
\text { (Argonne) }\end{array}$ & - & 1100 & $\begin{array}{l}39.6^{\ominus} \\
(21.8)\end{array}$ \\
\hline & $\begin{array}{l}\text { Wyodak } \\
\text { (Argonne) }\end{array}$ & - & 1100 & $\begin{array}{l}25.5 \\
(7.7)\end{array}$ \\
\hline & & & $\overline{T \text { particl }}$ & \\
\hline \multirow[t]{2}{*}{$\begin{array}{l}\text { Cold-Gas Laser Pyrolysis } \\
\text { This work }\end{array}$} & $\begin{array}{c}\text { Pittsburgh } \\
\text { (Argonne) } \\
\text { Illinois No. } 6 \\
\text { (PSOC 1098) } \\
\text { Wyodak } \\
\end{array}$ & & $\begin{array}{l}970 \\
900 \\
725 \\
900 \\
650 \\
550 \\
725 \\
\end{array}$ & $\begin{array}{l}42 \\
36 \\
19 \\
34 \\
29 \\
22 \\
19\end{array}$ \\
\hline & & & $\mathrm{T}_{\text {gas }}{ }^{\mathrm{a}}$ & \\
\hline \multirow[t]{2}{*}{ TGA-FTIR, Solomon } & $\begin{array}{l}\text { Pittsburgh } \\
\text { (Argonne) }\end{array}$ & & 900 & 23.2 \\
\hline & $\begin{array}{l}\text { Wyodak } \\
\text { (Argonne) }\end{array}$ & & 900 & $\begin{array}{r}9.0 \\
(21.0 \text { de- } \\
\text { mineralized })\end{array}$ \\
\hline
\end{tabular}

a. Final gas temperatures are $\sim 160^{\circ} \mathrm{C}$ below the final wall temperatures in the cool-gas EFR, and equal to the final gas temperatures in the hot-gas EFR. Final particle temperatures are equal to final gas temperatures in all except the laser pyrolysis.

b. Taken from Reference 18 , which utilizes a downward flowing, radiant-heating, entrained-flow reactor having cold initial gas.

c. Percent tar yield, obtained by combining the total volatiles yields and the figures given in Reference 18 for tar as a fraction of total volatiles yields.

d. Taken from Reference 19, which utilizes a downward flowing EFR reactor with similar final gas and wall temperatures.

e. Total hydrocarbon volatiles yields: the tar and hydrocarbon gas yiclds from the authors' data have been combined to give a maximum value for the tar that would have been produced had not some of it been cracked to gas. The values in parentheses are the actual tar yiclds reported in Reference 19.

f. Particle temperature (95th percentile), as determined through total radiance measured by imaging radiometer. The values given represent a temperature midway between the upper and lower limits obtained from the combination of radiance and particle-size distribution measurements. 
volatilities observed here are sinilar to those seen for the hot-wall, hot-gas entrained-flow pyrolysis tars described by Khan et al. ${ }^{11}$ In that process, the tars continue to be heated (to a much higher temperature) until they exit the drop-tube reactor. Furthermore, Freihaut concludes from his coal-gas pyrolysis results 18 that on a hundred-millisecond time scale, secondary reactions of evolved volatiles are minor at gas temperatures below $800^{\circ} \mathrm{C}$. Thus, the FI mass spectral analysis results should be considered representative of the tar as it left the coal particle. The implications of these limited volatilities are discussed in the next section, Mechanisms of Tar Transport.

FIMS analysis was also used to compare these laser-pyrolysis (LP) tars with a set of hottube entrained-ilow reactor (EFR) tars obtained from Advanced Fuel Research. These results are discussed in Reference 21 (which is also the fourth paper listed in the project publications list) but two major observations are noted here. First, the biggest differences between the EFR and LP tars were observed for the Wyodak coal, with the LP tars having two to three times as much catechol and other dihydroxybenzenes. Second, examination of temperature-evolution curves for individual masses produced during Py-FIMS analysis of the tars derived from the Pittsburgh and Wyodak coals revealed that essentially all the cresol and other monohydric phenols evolved during FIMS analysis were, for the EFR tars, pyrolytically generated on the hot FIMS probe; for the LP tars, they were preexisting. The larger amount of dihydric phenols in LP tars is expected, because dihydric phenols are well known to be subject to retrograde reactions and would be less likely to survive the EFR hot-gas conditions. The absence of pyrolytically generated monohydric phenols in LP tars goes hand in hand with the abundance of dihydric phenols in these tars: dihydric phenols are known to be highly subject to retrograde reactions, and further pyrolysis of some of these coupling products produces monohydric phenols. Thus in the EFR tars, which have been more exposed to conditions promoting secondary reactions, there are fewer dihydric phenols and more coupling products of these phenols. It is likely that cresols and other monohydric phenols are pyrolytically generated during FIMS analysis from coupling products of dihydric phenols. 22,23

\section{Mechanisms of Tar Transport}

Several observations made on the LP tars allow us to conclude that a substantial portion of the tar is released from the pyrolyzing coal by something other than an evaporative process: (1) the limited volatility of the LP tar under FIMS analysis conditions, (2) the physical appearance of the collected tar cakes, and (3) the very short lag times observed between the entry of the particles into the laser-heated region and the onset of tar (aerosol) release.

From the beginning of the LP runs, we found that the lag time between the entry of the particles into the laser-heated zone and the appearance of tar aerosols was no more than about $10 \mathrm{~ms}$. This short lag time raises the question whether, under these conditions, the major tar 
transport really involved diffusional transport of the newly generated tar, and then a vapor-liquid equilibrium at the condensed-phase/gas-phase interface. This vapor-liquid equilibrium has often been assumed, ${ }^{24,25}$ although Gray, ${ }^{26}$ for example, and Suuberg 27 have considered the role of explosive ejection in tar generation. The possibility of significant nonvapor transport was further highlighted by our observation that FIMS analysis of the tars shows substantial portions of some of them to be nonvolatile under the analytic conditions. This nonvolatile material is truly "tar"; it is completely soluble in THF, and microscopic examination shows essentially no char particles, which are easily distinguished from the yellow tar.

The final observation suggesting substantial nonvapor tar transport comes from the .ppearance of the tar collected during the pyrolysis of coals into which small amounts of hydrogenated coal tar have been loaded. Some of these differences can be seen in the photographs reproduced in Figure 12.

Beca:ise the added tar is black and the tar generated during pyrolysis is yellow, we expected the two materials, if they were co-vaporized, to produce a co-condensed tar aerosol that is black or some intermediate color. However, the tar-aerosol cake collected on the membrane filters generally shows a very distinctive pattern of swirls of black and yellow bands, indicating that the black and yellow tars have remained separate. The details of the aerodynamic factors producing these patterns aside, the two tar components clearly were generally not together in the vapor phase. Because this pyrolysis is steady-state flow, invoking sequential vaporization and transport of the two materials is difficult.* These results, taken together with those reviewed above, strongly support the movement of a substantial fraction of the tar from the interior of the coal by a nonvapor transport process during rapid coal heating for all four coals tested, but particularly the Illinois No. 6 coal.

The contribution of substantial nonvapor transport processes under rapid heating conditions would have a major bearing on the validity of the vapor-liquid equilibrium generally assumed 24,25 in the volatiles production models that are used in an attempt to understand or predict pulverized coal combustion behavior. On one hand, the inclusion of a nonvapor transport component in the models, if it allowed better prediction of behavior, would obviously be a significant step forward. On the other hand, if the inclusion of a "corrected" view of tar transport were not necessary for reproducing pyrolysis or combustion behavior, that finding would provide telling evidence that the

\footnotetext{
- Although the pyrolysis is operated under "steady-state" conditions, it is not a continuum on a microscopic scale. That is, the interparticle distance is large compared to the particle diameter, and the tar aerosol(s) are first delivered to the local region within the boundary layer surrounding the particle. If, for example, the preexisting tar applied during pretreatment were to be vaporized first and the indigenous tar (which had to be chemically generated) second, it is conceivable they would condense separately in time and/or space, forming different sized aerosols whose aerodynamic behavior in the collection train would be different. This scenario seems unlikely, but it cannot be ruled out.
} 


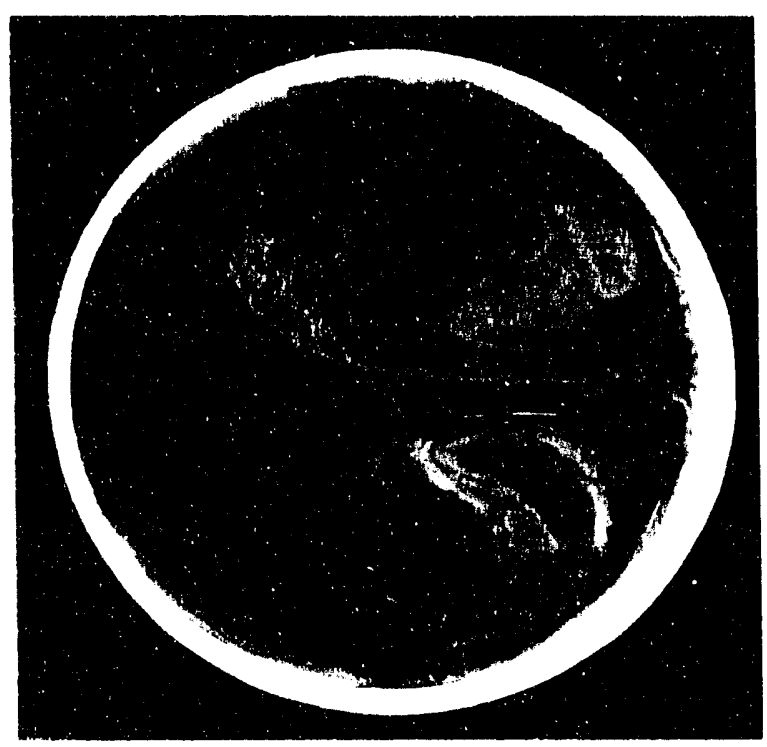

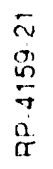

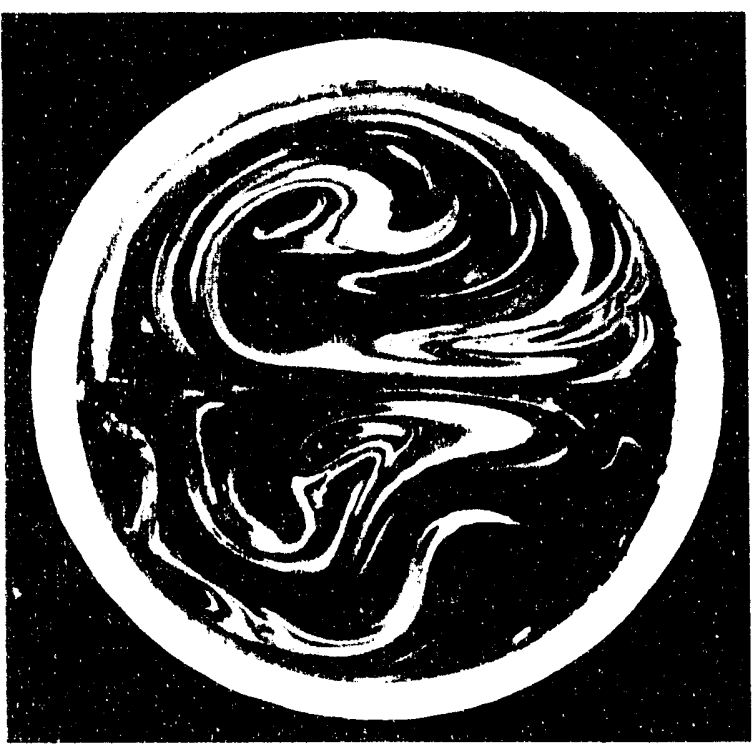

i

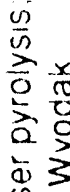

每

$E$
0
0

홍을

고응

응

号

ชั

产全哭

过先

등

“范范

동

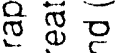

ऊั)

ช

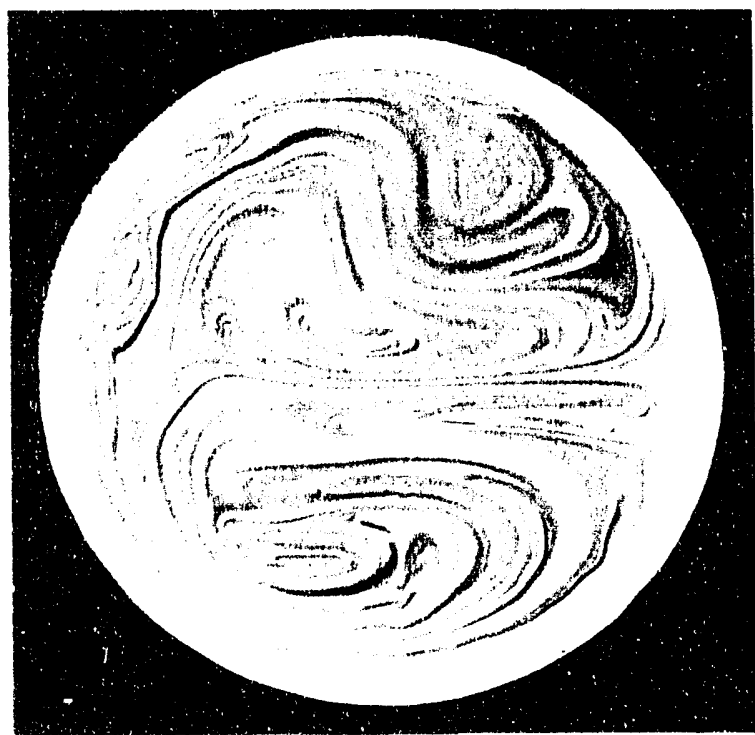

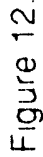


models can succeed through inadvertent parameterization, not necessarily because they incorporate the correct mechanistic picture.

\section{Comparison with Other Laser-Heated Coal Pyrolysis Approaches}

Of the more $r$ cent applications of laser heating to coal pyrolysis, the approach of Gat and coworkers at TRW28-30 is particularly relevant to our project. Other LP approaches include studies on electrodynamically suspended particles by Maloney and coworkers at METC, 31 -33 Sarofim and coworkers at MIT, 34 and Meuzelaar and coworkers at the University of Utah. 35

The approach followed in this project was similar to that used by Gat et al., $28-30$ who used a CW infrared laser (HF, $\lambda=2.7 \mu \mathrm{m}$ ) to heat from two sides a stream of coal particles entrained in an argon flow. In contrast to our approach, Gat and coworkers used a focused beam of very high power $\left(>2 \mathrm{~kW} / \mathrm{cm}^{2}\right.$ versus our $200 \mathrm{~W} / \mathrm{cm}^{2}$ ), heated the coal to much higher temperatures $\left(2000^{\circ}-3000^{\circ} \mathrm{C}\right.$ versus our $\left.500^{\circ}-900^{\circ} \mathrm{C}\right)$ in the waist of the focused beam, and did not collect tars or other volatiles but inferred their yields from ash tracer techniques. They used a three-color pyrometric temperature measurement technique, using light emitted at $0.8,0.95$, and $1.1 \mu \mathrm{m}$, that provides not only a measure of temperature but also an indication of the temperature measurement error. ${ }^{36}$ A comparison of measured rates is not very useful because of the large differences in temperature range. The differences between the TRW results and ours can be summarized by saying that their general goal was apparently to assess the total volatiles yield under very high heating rates and high final temperatures. Their approach (heating in a focused beam) was not designed specifically to ensure even illumination of all particles and did not collect any product tars; however, it did produce more reliable temperature measurements.

The approach of Maloney and coworkers $31-33$ involved heating electrodynamically suspended particles in an oxidizing environment to study the ignition process. The principal useful point of comparison is in the heating rates and temperatures at which volatiles evolution and other stages in the pyrolysis begin and end and in the conclusions reached about what limits the rates of evolution. Maloney concludes that "...the heavy volatile evolution was a mass transport controlled process involving bubble growth and transport." This conclusion does not seem easily reconciled with our conclusion that tar evolution is substantially a nonvapor, nondiffusive process; that is to say, to the extent that aerosol formation in a cold (or hot) gas occurs by what is essentially an ablation process, it will occur at the rate that the energy is supplied for that process. It will depend on heat transport, but it will not be diffusion-limited. 


\section{Comparison with Pyrolysis Data from the Literature}

Overall Yields. The tar yields obtained in this project are significantly higher, as expected, than those obtained with slower-heating pyrolysis techniques. This finding is particularly true for the lowest-ranked coal we studied, the Argonne Wyodak sample. As indicated above, it produces a tar yield close to that of the Argonne Pittsburgh coal. This result can be seen from the data summarized in Table 3, where the tar yields obtained from laser pyrolysis are shown along with those obtained by Solomon ${ }^{19}$ and Freihaut et al. ${ }^{18}$ in their respective hot- and cool-gas entrained-flow reactors. To compare total yields, we have listed, for both these EFR reactors, the tar yield and the tar-plus-all-organic volatiles to account for the increase in secondary tar cracking at the $1100^{\circ}$ and $1000^{\circ} \mathrm{C}$ final gas temperatures in these reactors over that in the $\sim 100^{\circ} \mathrm{C}$ argon flow of laser heated pyrolysis. The tar yields are higher in the laser-pyrolysis system, as the data in Table 3 show. There is some improvement even over the yields from the cool-gas reactor of Freihaut, perhaps because the heating rates in the United Technologies Research Center entrained-flow reactor system are only $2000-5000 \mathrm{~K} / \mathrm{s}$, five to ten times lower than in the laser heated system.

Previously published data on the dependence of volatiles yields on heating rate ${ }^{20}$ (at lower maximum heating rates) would lead us to expect some increased yield with heating rate, but perhaps not as much as is shown in Table 3. However, the differences seen here may be consistent with the observation by Solomon ${ }^{10}$ that, at heating rates of $10,000 \mathrm{~K} / \mathrm{s}$ or higher, even non-softening coals like lignites give chars that indicate melting took place. The retrograde reactions in the Wyodak coal may simply be more overwhelmed by the rapid tar production process (including explosive ejection of nonvolatile species) at $30,000 \mathrm{~K} / \mathrm{s}$ than they are at $5000 \mathrm{~K} / \mathrm{s}$. It is possible that the combination of the absence of convective heating, and the presence of radiative heating in depth-i.e., with a wavelength where the optical depth of the coal $(\sim 15 \mu \mathrm{m})$ is substantial compared to the $25-\mu \mathrm{m}$ radius of the coal particles-serves to maintain the surface of the coal in a more fluid state during the escape of tars from the interior of the coal particles. Thus it is not possible to say with any precision at just what heating rate the yield advantage apparently seen in the present laser-pyrolysis studies would first be encountered, or if this advantage would be diminished when the gas is hot and the irradiating wavelength is shorter, making intra-particle conductive heat transfer more important. A inore complete answer to this puzzle of heating-rate and heating mode also awaits more complete analysis of the tars from the respective studies by a single set of analytical techniques.

The high yields seen in this work, where the entire volume of the coal particle becomes hot and fluid at very nearly the same time, prompt us to make some additional comments on the impact of the heat delivery mode during coal gasification. Fletcher ${ }^{37}$ recently pointed out that the softening of coal particles during pyrolysis (heating in the presence of an inert gas) is substantially more 
pronounced than it is under combustion conditions. Moreover, the inhibition of softening observed under combustion conditions seems to apply even to coal particles that encounter radiative and convective heating after essentially all of the oxygen has been consumed. Thus, we would speculate that what inhibits the softening is not $\mathrm{O}_{2}$ itself, but some oxygenated radicals (e.g. $\mathrm{OH} \cdot$ ). The mechanism aside, however, these observations may carry profound implications for air-blown and oxygen-blown gasification. Now, if the goal of gasification (as in the Texaco gasifier) is to use very high temperatures to drive everything to $\mathrm{CO}$ and $\mathrm{H}_{2}$, then the impact of the oxygen on the coal fluidity may be essentially moot. However, if the goal (as in mild ga ification) is to maximize the yield of moderate size hydrocarbons, then it may be worthwhile, at least in principle, to focus on heat-transfer techniques that do not use the expedient of partial oxidation in the gasification chamber itself. On the other hand, if heat-transfer practicalities in large-scale operation make it impossible to achieve the goals of rapid heating and remote oxidative generation of heat at the same time, then the question seeming to deserve fundamental attention is how the presence of some oxygen, even under very fuel-rich conditions, substantially limits fluidity development.

Tar Production Kinetics. The question of tar production kinetics is not completely distinct from that of total yields, but comparing tar production in terms of defined first-order rate constants is also useful. We were at first surprised to (1) obtain substantial tar yields in the very short reaction time $(<90 \mathrm{~ms})$ during which even the hottest particles in the stream were no more than $550^{\circ}-650^{\circ} \mathrm{C}$ and (2) observe a lag time of no more than $10-20 \mathrm{~ms}$ between the entry of the coal into the laser-heated region and the readily visible onset of tar arrosol evolution. An awareness of the difficulties and uncertainties of ten encountered in temperature ineasurement in rapid-heating pyrolysis experiments prompted us to use several different approaches to calibrating the imaging radiometer for use in measuring small-particle temperatures and to consider carefully the uncertainties and probable error limits in our approach. These conceins are discussed in the section entitled Issues in Particle Temperature Measurement. Here we discuss our measured yields and temperatures in view of coal pyrolysis data in the literature.

Few pyrolysis studies in the literature report kinetic parameters that provide low-temperature rates as high as those that emerge from our laser-pyrolysis data. This finding is illustrated in the Arrhenius plot compiled from literature data by Solomon and Serio, ${ }^{8}$ reproduced here with some modification as Figure 13. To the original plot we have added a dashed rectangle bracketing our particle temperatures and devolatilization rate constants in the mid-range of our laser intensities and, for comparison, two point (open circles with a connecting line) extracted from the published data of Freihaut. ${ }^{18}$

The middle of our temperature range $\left(550^{\circ}-650^{\circ} \mathrm{C}\right.$ ) is where we have the most data and where we judge the temperature and yields to be best characterized; for PSOC 1098 Illinois No. 6 


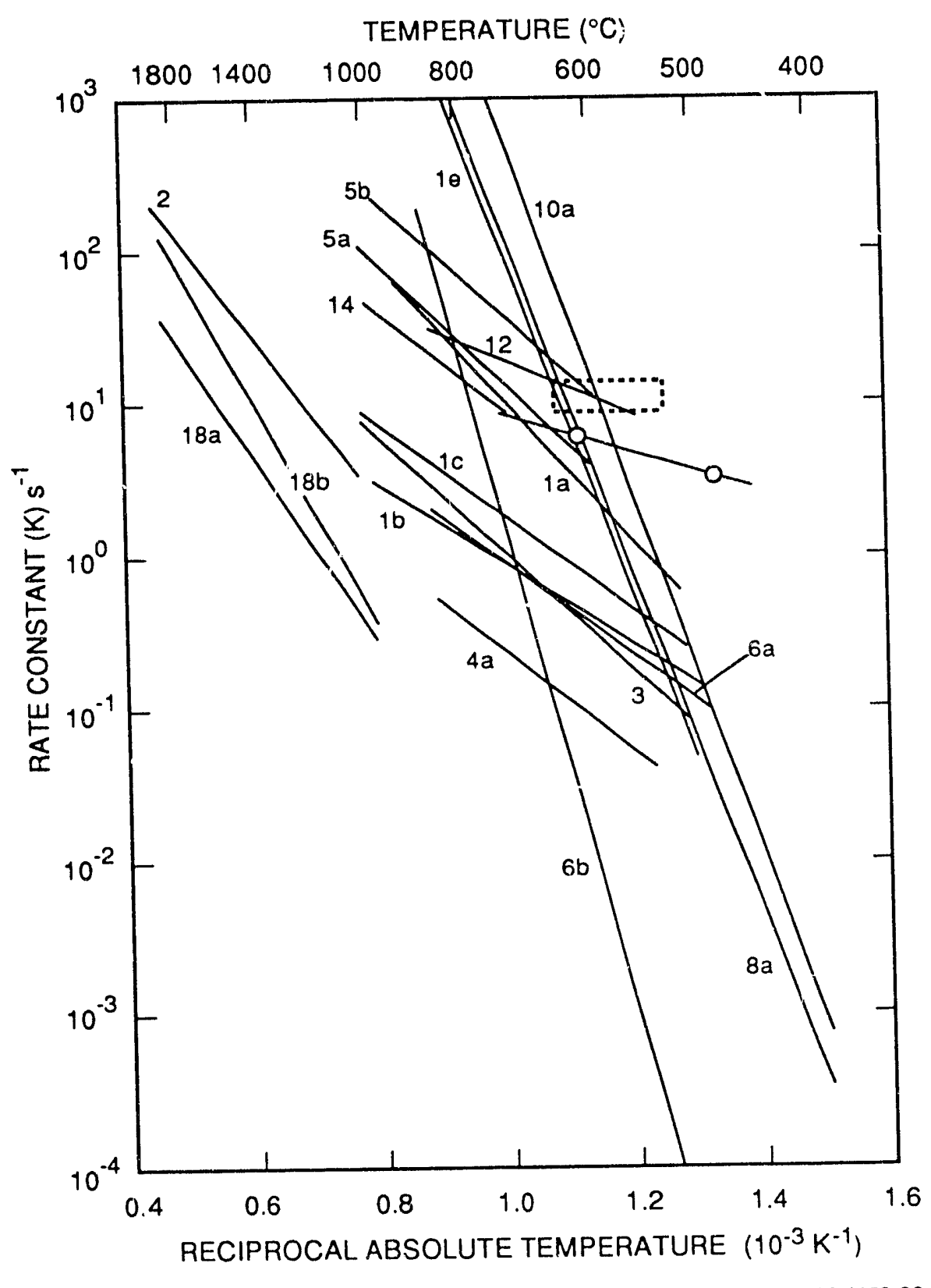

Figure 13. Comparison of kinetic data for tar (or total volatiles yields) in coal pyrolysis taken from literature sources.

Original figure with solid lines taken from Ref. 8 (lines 1, 5, 10, and 12 are data from Refs. $39,40,10$, and 41 ), circles and connecting line from Ref. 18, and dashed rectangle from this report. 
coal, the defined first-order rate constant at $650^{\circ} \mathrm{C}$ is determined to be in the range 9-14 $\mathrm{s}^{-1}$. We placed rate data for only one set of pyrolysis conditions on this plot, because the precision of the data does not warrant their being explicitly cast in the form of an Arrhenius plot. Nevertheless, it should be pointed out that the temperature dependence of the laser-pyrolysis tar yields apparent in a rough way in Figure 11 (above) is consistent with rather low activation energies. Specifically, conversion of representative tar yields from Figure 11 into apparent activation energies leads to values from 5 to $10 \mathrm{kcal} / \mathrm{mol}$. These values are somewhat low even for processes under diffusion control. Given the uncertainties involved, the significance of these values lies only in their general magnitude; that is, the temperature dependence is something like $10-20 \mathrm{kcal} / \mathrm{mol}$ or so, but it is definitely not 50 or $60 \mathrm{kcal} / \mathrm{mol}$. For comparison, we can look at the temperature dependence in the recent data of Freihaut and coworkers. ${ }^{18}$ These authors chose not to report their data as rate constants, let alone as activation energies, presumably because of the very same measurement uncertainties that we have discussed in this report. Nevertheless, from their reported residence times, temperatures and tar yields, rough rate constants can be extracted. Two such rate constants we have calculated from their published yields are shown as open circles in Figure 11; they correspond to an apparent activation energy of $\sim 5 \mathrm{kcal} / \mathrm{mol}$. Thus, tar yields derived from rapid pyrolysis in cold or cool gas atmospheres appear to show a rather lower temperature dependence than the higher values preferred by Solomon and coworkers, ${ }^{8}$ and we need to ask what conclusions can be drawn from this apparent discrepancy.

First, the discrepancy described above is not due to uncertainties in what tar yield to take as "100\% reaction," or to minor factors such as exact ash content of the entrained feed coal. Freihaut has suggested ${ }^{38}$ that the substantial yields observed 18 even at $500^{\circ}$ or $550^{\circ} \mathrm{C}$ reflect pre-existing "trapped" volatile material. If this is the case, then inclusion of this physically trapped material in the rate calculations would produce a temperature dependence that is spuriously low. However, Illinois No. 6 coals are not noted for having large amounts of extractable material. Nevertheless, if we assign $12 \%$ (maf) tar yield to this "pre-existing" tar, we find this raises the apparent activation energy, but only up to the 10 to $20 \mathrm{kcal} / \mathrm{mol}$ range. Thus we conclude that skewing the measured rate constants in either our data or that of Freihaut enough to bring the measured activation energies into the 50 to $60 \mathrm{kcal} / \mathrm{mol}$ range representative of rate limitation by weak-bond homolysis would stretch the limits of plausibility. The implications of this conclusion are discussed below.

Pyrolysis Activation Energies and the Distributed Activation Energy Model. For many years, ramped-temperature pyrolysis data have been fit with a mechanistic picture consisting of parallel first-order reactions (thermal bond scissions) having a distribution of activation energies. Reaction under these conditions, where a series of reactions come into play in sequence as the temperature is continuously raised, leads to an overall temperature dependence that 
can be less than that of any of the contributing reactions. However, this apparent lowering of the activation energy cannot happen with a temperature-jump experiment. In the true "T-jump" situation, there of course can be no reaction during heat-up; under these circumstances, the apparent activation energy will be a weighted average of those for all the contributing reactions. In other words, with a true temperature jump experiment, one cannot observe an overall activation energy which is less than that for any of the parallel first-order reactions. Thus, to the extent that the present laser-heated pyrolysis approximates a temperature-jump situation, any low activation energies observed will be low because a complex set of reactions (rather than a set of parallel first-order reactions) controls the rate of tar formation. Thus, we take the low temperature dependence evident in Figure 11 and in Freihaut's data in Figure 13 as supportive of bond cleavage by a complex sequence of reactions wherein many of the bond cleavages ultimately occur as a result of $\mathrm{H}$-transfer, either from aliphatic carbon ( $\mathrm{H}$-abstraction, $\beta$-scission) or to ipso aromatic carbon (H-donation, $\beta$-scission). Thus these results, though not of high precision, offer tantalizing support of our contention ${ }^{1}$ that bond cleavage in coal pyrolysis is not controlled simply by a parallel set of weak-bond cleavage reactions.

The reported or extrapolated rates from various sources vary over more than 5 orders of magnitude, as pointed out by Solomon and Serio. ${ }^{8}$ Only four of the groups whose data are shown in this figure had reported data on rare parameters that indicate rate constants in the range of 5 to 10 $\mathrm{s}^{-1}$ in the temperature range $500^{\circ}$ to $575^{\circ} \mathrm{C}$ : Anthony et al., ${ }^{39} \mathrm{Badzioch}$ and Hawksley, ${ }^{40}$ Solomon et al., ${ }^{10}$ and Freihaut 18,41 (lines $1 \mathrm{e}, 5 \mathrm{~b}, 10 \mathrm{a}$, and 12 and the open circles). The latter two groups have focused more than perhaps any other workers on the problem of determining correct particle temperatures during pyrolysis. Specifically, in a paper more recent than the Solomon review, Freihaut and coworkers ${ }^{18}$ report results from a hot-wall, cool-gas pyrolysis technique--akin in principle to our laser-pyrolysis approach-in which they observe tar yields of 10 to $15 \%$ at temperatures as low as $500^{\circ} \mathrm{C}$ (for a Pittsburgh seam coal with hot-zone residence times of $\sim 100 \mathrm{~ms}$ ). This yield is very close to the range of our rate data. In contrast, many reports (primarily from heated-grid pyrolysis studies) suggest that reaction times of up to $1 \mathrm{~s}$ are necessary for the bulk of tar evolution to occur, even at $600^{\circ} \mathrm{C}$. Many of these older studies are represented by the Arrhenius plots below and to the left of the region represented by the temperatures and evolution times (approximately indicated by the dashed box in Figure 13) measured in this project.

The interesting observation that emerges from the data in this project (and from that of Freihaut et al. ${ }^{18}$ ) is not that tar evolution occurs at $500^{\circ} \mathrm{C}$ (this fact is well known), but that it occurs so rapidly at such low temperatures. It is interesting to question why our results lie outside the range of those from the great bulk of coal pyrolysis kinetic studies (as represented in Figure 13). 
In addition to the fact that particle temperature measurements can always present uncertainties, we note that few if any other studies involve such rapid heating to such low temperatures (i.e., $\leq 600^{\circ} \mathrm{C}$ ). In most studies driven by interest in the $\sim 10^{5}-\mathrm{K} / \mathrm{s}$ heating rates relevant to pulverized coal combustion, the investigators have also been interested in the temperature range most applicable to such combustion (i.e., $>1000 \mathrm{~K}$ ). The use of rapid heating to low temperatures, together with more precise particle temperature measurements, should provide needed leverage at the low-temperature end of the coal pyrolysis temperature spectrum and, in so doing, may help to provide some distinction among the widely varying apparent activation energies evident in Figure 13. Such data, as discussed above, should also help to clarify the mode(s) by which nascent tar is transported out of the coal particle.

\section{Issues in Particle Temperature Measurement}

Reliable temperature measurement is the key to obtaining reliable information from a hotwall, cold-gas pyrolysis technique. In contrast to a hot-wall, hot-gas pyrolysis approach, in which all coal particles quickly approach the temperature of the gaseous surroundings (which is, in turn, straightforwardly measured with thermocouples), pyrolysis in a cold gas necessitates a pyrometric temperature measurement. After the initial laser-pyrolysis experiments in which we used a disappearing filament pyrometer, we used close-up infrared video imaging with an Inframetrics Model 600 Imaging Radiometer to determine particle temperatures and temperature distributions. This instrument is very convenient to use. A telephoto lens with a close-up attachment provides a macro capability. The camera is then used to view (perpendicular to the axes of particle travel and laser illumination) the approximately $0.5-\mathrm{cm}$-long laser-heated region. This approach provides a video record covering the entire laser-heated region at once, a determination of number density and spatial and velocity distribution, and the temperature distribution of a set of moving particles.

When operated in the fast-line scan mode, the radiometer scans the same horizontal line every $125 \mu$ s, essentially providing a viewing slit that the entrained particles pass in their upward flow. The temperatures and velocities of the particles are determined from the intensity and length of the images produced as the particles pass the slit.

The Inframetrics Model 600 provides an image in the EIA RS-170 standard video format, achieved by means of a vertically and horizontally scanning mirror system and a high-sensitivity mercury-cadmium telluride detector. The radiometer normally provides straightforward and accurate temperature measurements for relatively massive objects of known emissivity. Because of the limited response time of $\mathrm{HgCdTe}$ detectors, the design of the Model 600 represents a compromise between high resolution and the ability to scan rapidly enough to capture moving targets. As previously discussed, when the objects are large enough that they completely fill an 
area equal to or greater than that imaged onto a single pixel [i.e., one instantaneous field of view (IFOV)], the emitting area is in effect defined by the particular set of optics in use. As the camera moves farther away from the object, the area filling an IFOV increases with the square of the distance, but the fraction of the light emitted from this growing area that falls on the detector will decrease, also with the square of the distance.

There is one other size requirement. The rapid rate at which the concinuously moving mirror allows the detector to sweep across the object means that the detector charge is written into storage every $0.3 \mu \mathrm{s}$. The limited response time of the $\mathrm{HgCdTe}$ detector means that the surface being observed must have the same temperature for $>5$-IFOVs so that the detector can achieve $>98 \%$ of its steady-state response.

If either of the above requirements is not met, a calibration factor must be used so that the correct temperature can be measured. If the size of the object is known, this calibration can be either calculated or determined experimentally by using objects of the same size and emissivity with known temperatures. For objects of about $50 \mu \mathrm{m}$, the calibration factors are large and exert great leverage on the measured temperatures. Thus, calibration is particularly important for our experiments. We first determined the particle temperature using factors calculated from geometric considerations, which are outlined below. Because the resulting temperatures seemed too low by comparison with literature data and because significant potential error is inherent in these large adjustments, we have also experimentally determined the calibration factors. More careful examination of the literature data has since indicated that some of the various "measured" pyrolysis temperatures reported may be as much as several hundred degrees in error, and recent experiments in which the temperature measurements are more reliable ${ }^{18}$ suggest fairly rapid tar formation in the vicinity of $500^{\circ} \mathrm{C}$. Our laser-pyrolysis data and the literature data were discussed earlier in this report; in this section we focus on the details of the ternperature measurement and the potential/probable errors involved.

Geometrically Calculated Calibration Factors. This approach to the temperature measurement of small objects was used after consultation with Dr. Gary Orlove of Inframetrics, Inc. in Billerica, MA. With the $3 \times$ telephoto and 6-in. close-up lens attached, the viewing distance is fixed at 6 in. At this distance, one IFOV is $94 \times 94 \mu \mathrm{m}$; the calibration factors are obtained by considering what fraction of the vertical field of view is filled by a particle of given vertical size and what fractional detector response is achieved in the time required to sweep across the horizontal dimension of the particle. These ge ometric considerations are shown schematically in Figure 14, in which the Model 600 detector response or "slit response function" (SRF) is plotted. 
In this figure, the horizontal axis corresponds to the object size (width) with the $3 x$ telephoto and 6-in. close-up lens attached. As Figure 14 suggests, for an object that is large in the vertical direction but that corresponds to only one IFOV $(94 \mu \mathrm{m})$ in the horizontal direction, the

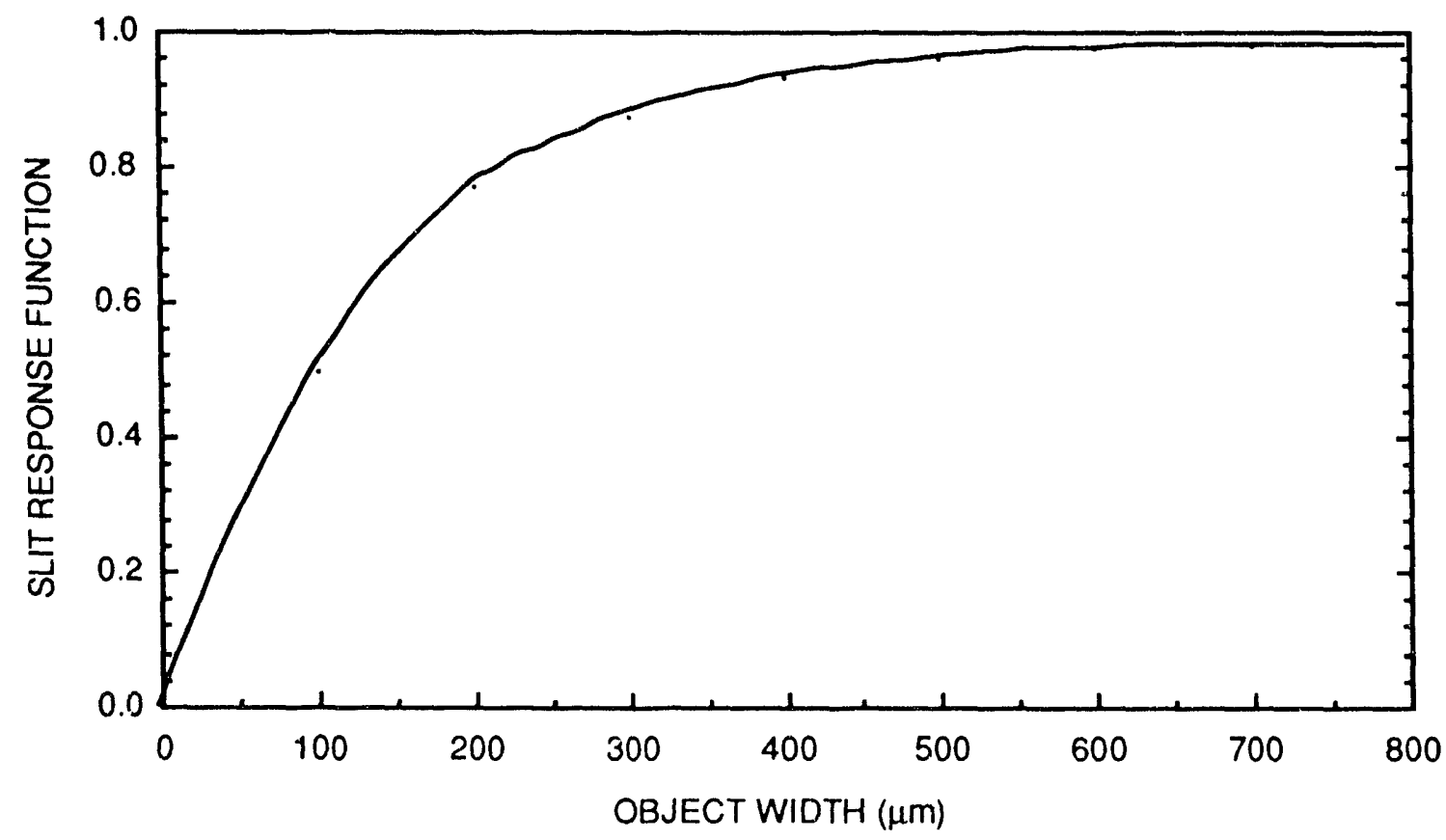

Figure 14. Slit response function for horizontal scanning of vertical slits (SRFdiam), as a function of slit width, using Inframetrics Model 600 equipped with $3 X$ telephoto and 6 -in. close-up lens (data from Inframetrics, Inc.).

detector reaches half of its full-scale response; thus the radiometer will measure only half the true radiance. If the object is, in addition, small in the vertical direction, then the measured radiance will be lower by an additional factor, corresponding to the fractional filling of a rectangle of height equal to one vertical IFOV and width equal to the particle width. The net calibration factor is the product of this fractional area and the modified slit response factor corresponding to the object (particle) diameter. If the background behind the particle (filling that portion of an IFOV not filled by the particle) emits a significant amount of light compared with the particle, this factor must also be accounted for. In this case, where the walls of the laser-pyrolysis cell are typically about $50^{\circ} \mathrm{C}$ (apparent black body temperature, $\sim 30^{\circ} \mathrm{C}$ ), it is not a significant additional correction factor for particles larger than about $80 \mu \mathrm{m}$ but is quite substantial for a $50-\mu \mathrm{m}$ particle below about $600^{\circ} \mathrm{C}$. All these factors are combined as shown below, where the calibration factor is calculated via 


$$
\text { True particle radiance }=\frac{\text { Measured radiance }-\left(1-\mathrm{SRF}_{\mathrm{eff}}\right) \times \text { Background radiance }}{S R F_{\mathrm{eff}}}
$$

where $\mathrm{SRF}_{\mathrm{eff}}$ is the effective slit response factor for an object of diameter $\mathrm{D}$ and is given by

$$
\mathrm{SRF}_{\mathrm{eff}}=\mathrm{SRF}_{\mathrm{part} \text { diam }} \times \mathrm{C}_{\mathrm{coal}}
$$

$\mathrm{SRF}_{\text {part diam }}$ is the slit response factor for an object having a width equal to the particle diameter (and an infinite height), taken directly from Figure 14 above, and $\mathrm{C}_{\mathrm{coal}}$ is the fractional filling of a slit with a height of one IFOV and a width of one particle diameter.

$$
\mathrm{C}_{\text {coal }}=\frac{\text { Area }_{\text {particle }}}{\text { Diam }_{\text {particle }} \times 1 \text { IFOV }_{\text {vertical }}}
$$

After the factor given by $S R F_{\text {eff }}$ is used to obtain the true particle radiance (measured, in this case, from 7 to $10 \mu \mathrm{m}$ and from 11 to $12 \mu \mathrm{m}$ ), the latter must then be converted into temperature by the temperature-dependent relationship between emitted light and temperature. The calibration of the radiometer and auxiliary optics was performed using a massive object of known emissivity at 400 to $700^{\circ} \mathrm{C}$. For particles of $57 \mu \mathrm{m}$, slightly below the nominal median particle diameter in a 250/270-mesh screen fraction, the adjustment converts a raw measured temperature of $175^{\circ} \mathrm{C}$ to an actual temperature of about $740^{\circ} \mathrm{C}$. The extent of the adjustment diminishes rapidly with increasing particle size. For $70-\mathrm{mm}$ particles, a raw temperature of $175^{\circ} \mathrm{C}$ is converted to about $480^{\circ} \mathrm{C}$.

\section{Calibration of the Radiometer for Small Particles by Using a Masked}

Graphite Target. The Model 600 Radiometer normally provides straightforward and accurate temperature measurements for relatively massive objects of known emissivity. When the objects are large enough to completely fill an area equal to or greater than that imaged onto a single pixel (i.e., one IFOV), the emitting area is, in effect, defined by the particular set of optics in use. As an alternative to the calculation of the fractional filling of one IFOV achieved by particles of various sizes, we used masks with circular holes in sizes chosen to mimic particles covering the 50 - to $125-\mu \mathrm{m}$ size range of interest for pyrolysis of a $250 / 270$ screen fraction. These masks were placed in front of a graphite block of known emissivity and temperature.

We first considered using masks with holes covering the actual size range of the char particles produced in our pyrolysis experiments. However, that method would necessitate accounting for the effects of diffraction (because the hole sizes would be on the same order as the 7- to $12-\mu \mathrm{m}$ wavelength range used for temperature measurement) as well as those of a mask comparable in thickness to the hole diameter. Even though the light passing through the hole 
would in our case undergo less spreading by diffraction, because the graphite block was not a collimated light source, we could not satisfactorily place an upper limit on the extent of the effects of diffraction. Furthermore, the apertures readily available from electron microscopy suppliers do not constitute broad holes in a thin mask. For instance, a $75-\mu \mathrm{m}$ aperture obtained from Ernest Fullam Associates is commonly cut in 2-mil-thick (50- $\mu \mathrm{m}$-thick) stock, and consultation with technical staff there revealed that reliable use of substantially thinner material is difficult for them. For these reasons, we decided to record apparent temperatures while viewing the heated block through holes roughly 25 times larger at correspondingly larger viewing distances. In this way, the same fractional filling of an IFOV is achieved for a $1.5-\mathrm{mm}$ hole at an object distance of about $350 \mathrm{~cm}$ as for, say, a $57-\mu \mathrm{m}$ particle viewed at our normal close-up viewing distance of $15 \mathrm{~cm}$ (6 in.).

The masks were cut from black anodized aluminum sheet so that the emissivity of the background (i.e., the area surrounding the hole) would be the same as that of the anodized interior of the pyrolysis cell. The holes ranged from 1.56 to $3.97 \mathrm{~mm}$ in a sheet $1 \mathrm{~mm}$ thick. At a viewing distance of $365 \mathrm{~cm}$, these holes provided light from the same apparent area as holes ranging from 57 to $146 \mu \mathrm{m}$ at our normal close-up viewing distance. An iris having an aperture adjusted to be slightly larger than that in the particular mask being used was placed between the mask and the graphite block to limit heating of the mask. A flow of compressed air across the face of the mask was used to hold its temperature at the same background level achieved by the pyrolysis chamber interior during a typical pyrolysis run. The "true" temperature of the 3-in.-diameter, 2-in.-long graphite cylinder was determined by a platinum resistance thermometer in a 1/4-in. hole drilled $3 / 8$ in. from and parallel to the viewed face of the cylinder. All surfaces of the graphite except the end being viewed were wrapped with $\sim 1$ in. of spun silica to minimize heat loss and temperature gradients. The graphite block was heated to $700^{\circ} \mathrm{C}$ (the temperature limit of the resistance thermometer), and the apparent temperatures were recorded through holes of different sizes as the graphite block slowly cooled. In this way, the series of calibration curves shown in Figure 15 was developed.

After the data shown in Figure 15 were recorded, the camera-target distance was decreased by an amount calculated to have the $1.56-\mathrm{mm}$ hole (normally the $57-\mu \mathrm{m}$ mimic) subtend the same angle as the $2.38-\mathrm{mm}$ hole (normally the $87-\mu \mathrm{m}$ mimic) to determine whether the finite length of the hole (which is relatively most important for the 1.56- $\mathrm{mm}$ hole) significantly affects the image of the light passed by the hole. There was evidently no proble.n with "tunnel" effects, because this change in distance resulted in the image of the 1.56-mm hole registering the same apparent temperature as had the $2.38-\mathrm{mm}$ hole at the original distance. 
The size of the adjustment required to convert apparent temperatures to true temperatures, as indicated in Figure 15, is quite substantial, particularly for particles at the smaller end of our distribution. For example, a $57-\mu \mathrm{m}$ particle at $500^{\circ} \mathrm{C}$ (having the same emissivity as the graphite block) will register an apparent temperature of only $160^{\circ} \mathrm{C}$, while a $116-\mu \mathrm{m}$ particle at $500^{\circ} \mathrm{C}$ will give an apparent temperature of $304^{\circ} \mathrm{C}$. While the size of the required temperature adjustment is hardly ideal for our purposes, it is the result of design trade-offs that Inframetrics, Inc., had to make to achieve rapid IR imaging capability for objects only marginally above ambient

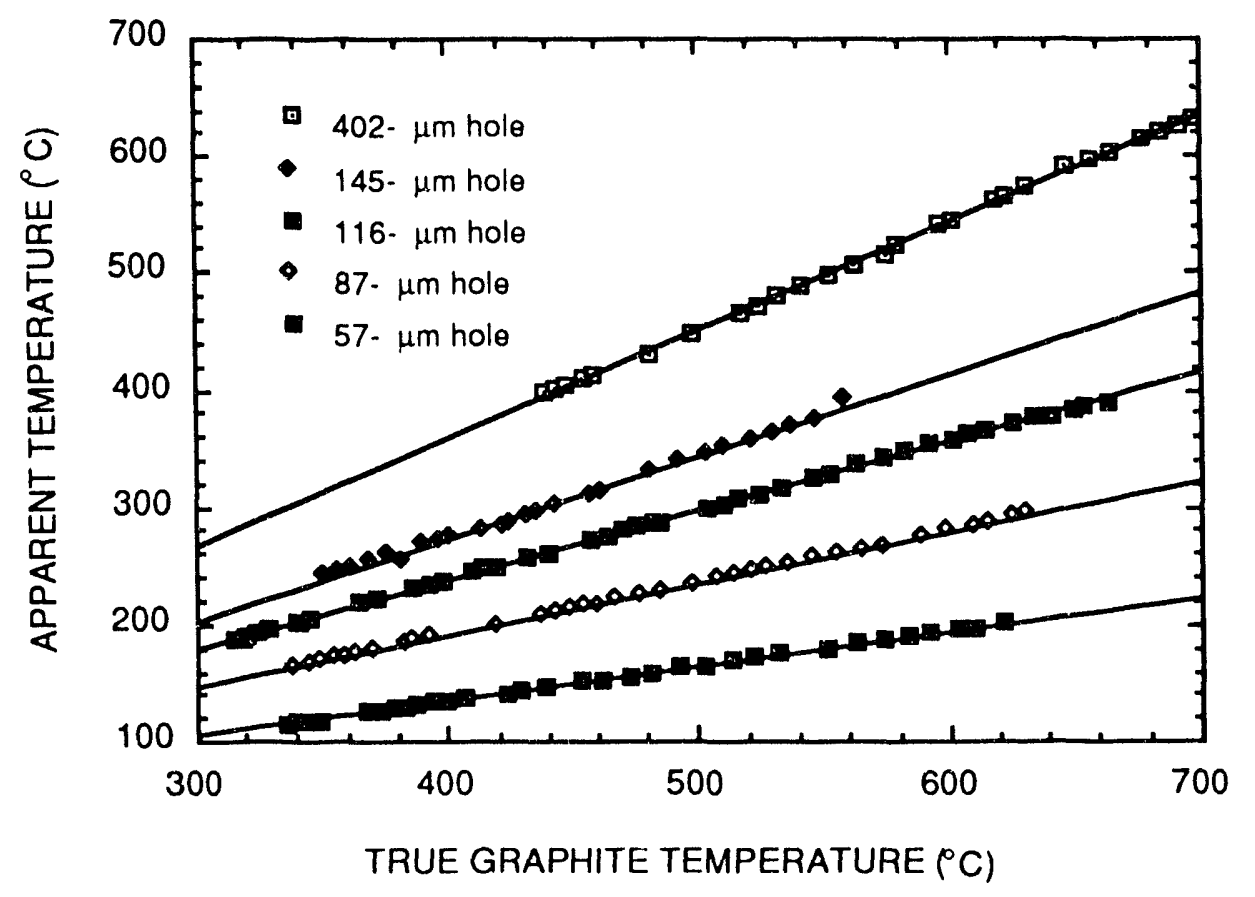

Figure 15. Temperatures measured with the Inframetrics Model 600 as a function of true temperatures for a black body viewed through a range of hole sizes chosen to mimic micron-sized objects.

temperature. For those of us working on this project, it was the price we paid for the convenience of applying this existing imaging capability to our low-temperature entrained-flow pyrolysis conditions. [The two-color version of the Model 600 would be nearly ideal for our purposes, but it costs nearly twice as much $(\$ 120,000)$, and one was not available to us at SRI.] In using these calibration curves, we must therefore (1) obtain accurate particle-size distributions for the chars, (2) combine them with the apparent temperature distributions in an appropriate manner, and (3) carefully assess the uncertainties in the process.

The curves in Figure 15 provide a measure of the temperature adjustment required for small particles. The slope of the fitted straight lines (i.e., the ratio of apparent temperature increase to 
true temperature increase) increases from 0.30 for $57-\mu \mathrm{m}$ particles and approaches 1.0 as the particle size increases beyond the point where a single particle fills an entire IFOV and where the particle is imaged onto the $\mathrm{HgCdTe}$ detector long enough for the steady-state voltage to be registered.

The curves in Figure 15 do not achieve a slope and intercept of exactly 1.0 and 0 , respectively [the actual measured value reached 0.92 for $402-\mathrm{mm}$ particles, with no significant increase as the particle (hole) size is increased further], because the optics and emissivity are slightly different from those in the original calibration. This factor is taken into account by determining the apparent temperature of an unmasked graphite surface of known emissivity and temperature using all the optics (including the $\mathrm{KC}$ pyrolysis chamber window) that are in place during a pyrolysis run. This calibration curve is shown in Figure 16.

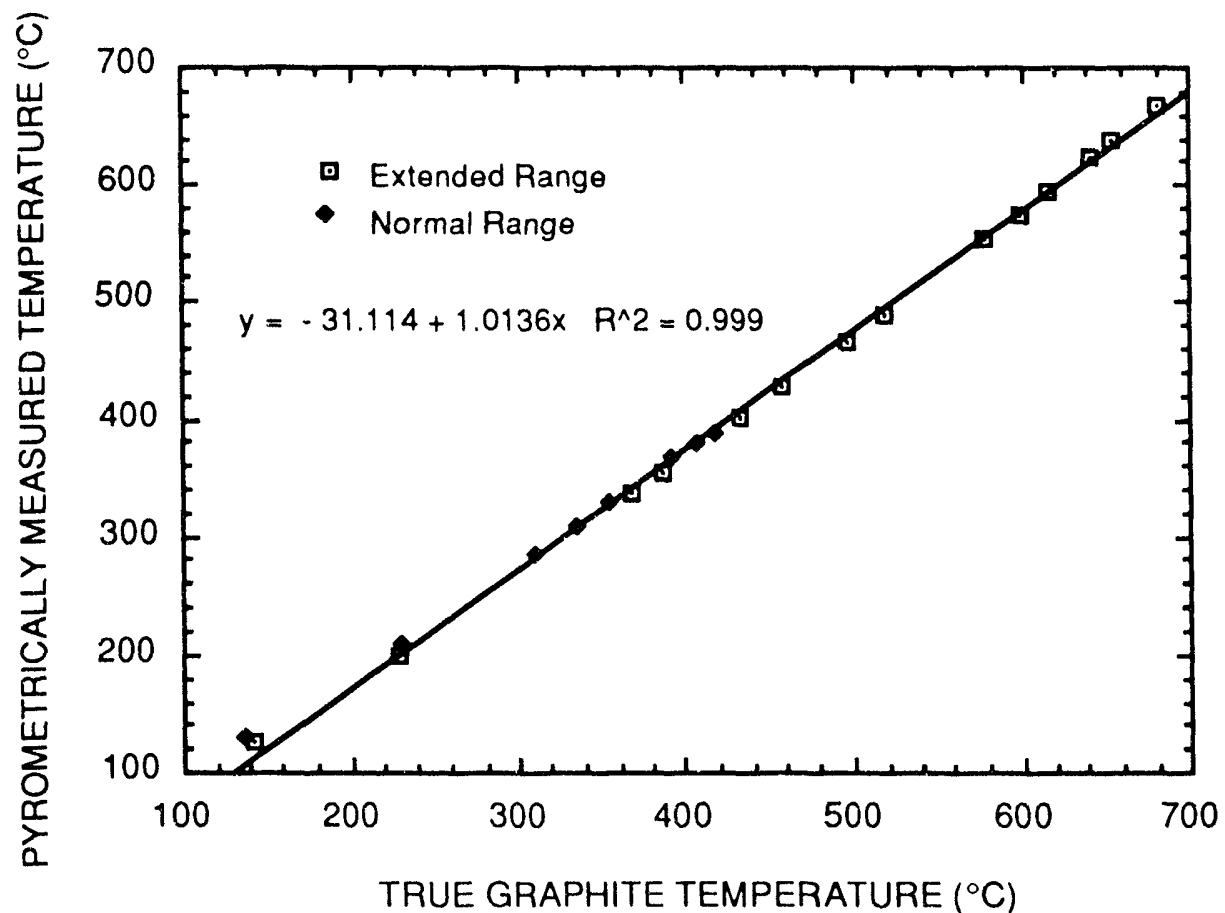

Figure 16. Raw temperatures determined with the Inframetrics Model 600 for an unmasked graphite body of known temperature by viewing through all optics used in looking into the pyrolysis cell.

The precision of the calibrations shown in Figures 15 and 16 is quite good. In combination, they allow us to correct for both the geometric factors and the special optics that apply during normal pyrolysis runs. With these two sets of calibrations, any indicated (i.e., 
apparent) temperature originating from the total radiance measurement of the imaging radiometer can be converted to the true temperature, assuming that the cross-sectional area and the emissivity of the particle in question are known.

\section{Combination of Particle-Size Distributions of the Recovered Chars with} Measured Temperature Distributions. Because the resolution of the radiometer image is not sufficient to accurately measure particle size in the 5()- to $150-\mu \mathrm{m}$ range of interest in this work, we cannot determine the temperature of any particular imaged particle. However, because heat transfer considerations dictate that the $\Delta \mathrm{T}$ of any particle will be proportional to the particle diameter, we expected the largest of the original coal particles to achieve the highest steady state temperatures. This expectation has been verified, at least with respect to the original coal particle size. Figure 8 (above), shows the particle-size distribution for the raw coal (obtained from a laser-off run) and for the char recovered from a rather low temperature run (tar yield, 13\%). The particle-size distributions, as described earlier, are obtained from photomicrographs of the recovered chars by using a computer-operated LECO 2001 image analyzer.

Comparison of the two profiles shown in Figure 8 makes it clear that in this case the laser heating has removed most of the larger particles from the original distribution $(60-70 \mu \mathrm{m}$ in diameter) and displaced them to a higher diameter (70-100 $\mu \mathrm{m})$. In other words, clearly the larger particles are heated the most and, under the circumstances of this particular experiment, are recovered as more swollen char particles. However, the situation is more complex than we had originally anticipated.

Many coals of course swell significantly during heating. Because the important diameter for the final temperature is clearly the fully swelled diameter, we had originally assumed that the particles that swell would be heated still further as a result of the swelling. Thus, heat transfer considerations would seem to indicate that a $60-\mu \mathrm{m}$-diameter particle that swelled to $66 \mu \mathrm{m}$ would experience a $10 \%$ higher $\Delta \mathrm{T}$ than a $60-\mu \mathrm{m}$ particle that did not swell. However, this conclusion is correct only if the optical density of the particles is not decreased during the swelling/devolatilization process. From our microscopic examination of the char particles recovered after pyrolysis under a range of conditions and from some literature data on absorption and emission of IR radiation by coal particles, ${ }^{14,15,42}$ we now conclude - on the basis of (1) an optical thickness (at $10.6 \mu \mathrm{m}$ ) on the order of $15 \mu \mathrm{m}$ for the original coal, $15,43(2)$ the increased cross-section area of the swollen coal, and (3) the loss of volatile matter during swelling - that the swollen 250/270mesh particles will actually have lower final temperatures than particles of the same size that do not swell. Thus, the larger particles in the original size distribution will heat the most (albeit more slowly than smaller particles); but as they begin to swell (i.e., spread their absorbing material over a larger cross-section area) and lose volatile matter, their optical density will actually decrease and 
they will achieve a lower steady-state temperature in the constant irradiation/convection environment than if they had not swelled.

Another result suggesting that the largest char particles (the cenospheres) are indeed not the hottest particles is the observation that the average char particle size does not seem to increase with increased laser intensity. This finding is in contrast to what we might have expected from the literature on swelling as a function of heating rate, in which higher free-swelling indexes are typically observed when the heating rate is increased, because of increased fluidity. ${ }^{44}$ However, more recent data at high heating rates show a heating rate/final temperature limit above which there is no particle swelling. 37,45 Examination of the recovered char particles in these studies and ours shows that, at heating rates higher than about $10,000 \mathrm{~K} / \mathrm{s}$, gas escapes primarily by local formation and rupture of bubbles without a significant increase in overall particle diameter. In other words, the coal fluidity is so high that the "balloons" pop before they can be blown up very far. If the coal mass is sufficiently fluid, this reaction can result in a net shrinkage of the intact char particles as mass is lost to the gas and aerosol phases.

This reversal at high heating rates of the generally observed re!ationship between swelling and heating rate and the realization that the optical density of coal particies in this size range will actually decrease with swelling both bear directly on our original assumption that the largest char particles would necessarily be those that attained the highest temperatures. Accordingly, we were forced to change somewhat the way in which the apparent temperature and particle-size distributions are combined to obtain the corrected temperature distribution in the laser-heated zone.

From the decrease in absorption with swelling discussed above, we conclude that the hottest particles will not be those that are most swollen (i.e., those having diameters of 70 to $100 \mu \mathrm{m}$ ). We also know that the hottest particles will not be the smallest ( 45 to $55 \mu \mathrm{m}$ ), because convective heat loss is most favorable to these small particles. The hottest particles will be those in the center to upper end of the original particle-size distribution $(\sim 55$ to $65 \mu \mathrm{m})$ that have not swollen very much (or have swollen somewhat and collapsed). Thus, we can now confidently adjust the raw temperature data by stating that the hottest particles are not less than 55 or more than $65 \mu \mathrm{m}$ and that the cooler particles consist of both larger and smaller ones. This regimen results in adjustments for the cooler portion of the $\mathrm{ra}^{\prime} \mathrm{N}$ temperature distribution that are both smaller and larger (for the largest and smallest particles, respectively) than those for the hotter portion and in a distribution of peak temperatures in the form of a band narrower at the higher range and broader at the lower temperatures.

The net result of the new calibrations and this new procedure is that the band of temperatures is somewhat broader than that derived earlier, but the general result--observation of 
substantial tar yields at remarkably low temperatures-is fundamentally unchanged. This finding can be seen by comparing the adjusted temperature distribution with the values derived earlier from the geometric correction factors and the assumption that the most swollen particles reach the highest steady state temperatures. Figure 9 (above) is a modification of a figure presented in the Proceedings of the 1990 Contractors' Meeting, showing both the original plot of derived temperature versus cumulative percentage of particles and a band of temperatures derived from similar data based on considerations discussed here.

The original particle temperatures in Figure 9, represented by the boxes, are from a run using the Illinois No. 6 coal (PSOC 1098) in which the tar yield was 13\%; the raw temperature data were adjusted using the geometrically derived adjustment factors discussed above. Data shown in Table 4 and shown in Figure 9 as triangles (particle size) and vertical bars representing

Table 4

\section{PARTICLE-SIZE DISTRIBUTION AND RAW AND ADJUSTED TEMPERATURE DISTRIBUTIONS FOR A PYROLYSIS RUNa YIELDING 33 WT\% TAR}

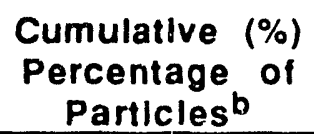

Raw
Temperature
$\left(\mathrm{C}^{\circ}\right)$

12

40

82

85

92

98 (C)

Diameter
$(\mu \mathrm{m})$

Adjusted Diameter Range
for Temperature
Adjustment (um)

45-70

45-70

50-70

55-65

$55-65$

$55 \cdot 65$
Temperature Range $\left({ }^{\circ} \mathrm{C}\right)$

$246-197$

$337-260$

$400-323$

455-407

540-472

$630 \cdot 542$

aRun 1-29-91b

oThe cumulative percentage of particles that are "undersized" with respect to either temperature or diameter.

temperatures (and the dotted lines drawn from them) are from a more recent experiment in which the raw temperature data were adjusted by means of the hole-size calibrations described above. The tar yield in this latter experiment was $25 \mathrm{wt} \%$ (significantly higher than that for the experiment shown in the original figure), the particle-size distribution was somewhat smaller, and the band of 
derived temperatures was somewhat higher. The smaller particle-size distribution for the recovered char in the experiment with higher tar yield and temperature was initially surprising but is in accord with some other data on coal swelling. ${ }^{37,45}$ The principal point is that the original result - that substantial tar yields are produced in 50 to $100 \mathrm{~ms}$ when the bulk of the particle mass is heated no higher than the $450^{\circ}$ to $550^{\circ} \mathrm{C}$ range--is supported by the experimental calibrations for smallparticle temperature modsurement. Table 4 shows the char diameter ranges used for adjusting the raw temperatures to the particle temperatures shown in Figure 9.

The temperature distributions shown in Figure 9 and Table 4 may appear too broad to provide much information on temperature-dependent pyrolysis rates. However, this bracketing of the temperature adjustment was done very conservatively; $\sim 80 \%$ (mass percentage) of the feed coal falls in the $57-$ to $71-\mu \mathrm{m}$ range, which corresponds to 50 to $95 \%$ (cumulative percentage) of the particles.

Error Limits in the Temperature Measurement. The major source of uncertainty in determining the distribution of particle temperatures is the ability to assign an emitting area (particle size) to any given, individually measured particle radiance. This uncertainty is significantly greater than the measurement precision, which, as can be seen from Figures 15 and 16 above, is better than about $5^{\circ} \mathrm{C}$ on the uncorrected temperatures and $15^{\circ} \mathrm{C}$ or less on the corrected temperatures. We conservatively associated a given particle size with a given portion of the temperature distribution; we tried to make assumptions so that the higher values in our band of derived temperatures really represent upper limits to the probable particle temperatures. Our choice. of limits can best be viewed in Figure 8 (above). The portion of the cold-flow size population most obviously "missing" after pyrolysis is the 57- to $71-\mu \mathrm{m}$-diameter portion (accounting for 50 $w t \%$ of the original feed material). Of the particles in this range, heat transfer considerations dictate that the original $71-\mu \mathrm{m}$-diameter particles will tend to be heated to the highest temperatures.

The question to be addressed is, then, will these hottest particles swell, stay at about $70 \mu \mathrm{m}$, or shrink? If these particles swell above $70 \mu \mathrm{m}$, calculations show that the loss in absorbance (caused by mass loss on pyrolysis, together with spreading of the absorbing material over a larger area) will be greater than the increase in cross-sectional area and consequently the steady-state temperature will decline. Thus, the majority of the hottest particles will definitely not be above about $70 \mu \mathrm{m}$. At the other extreme, how much is a $71-\mathrm{mm}$ particle likely to shrink because of volatiles loss and bubble collapse while it is in a very fluid state? About a $30 \%$ increase in density would be required for a particle originally $70 \mu \mathrm{m}$ to shrink to, say, $55 \mu \mathrm{m}$ while losing only about $40 \%$ in mass (i.e., the approximate volatiles yield). This increase in density is unlikely and even so would not be enough to compensate for the mass loss and the more effective convective cooling of the smaller particle. From these considerations, we conclude that the size 
limits on the hottest-appearing particles from our typical 250/270-mesh feed can easily be set at 50 $\mu \mathrm{m}<\mathrm{D}<70 \mu \mathrm{m}$.

Once we recognize that the hottest particles ci nnot be over 70 or under $50 \mu \mathrm{m}$, these limits, together with the observed tar yields and the optical dt pth of the coal particles, set the associated emissivity values. The temperature brackets derived fr $\mathrm{m}$ the 70 - and $50-\mu \mathrm{m}$ limits are lower than we might expect, because of a compensation between gcometric and emissivity factors. The 70$\mu \mathrm{m}$ assumption, which carries a relatively small geometry -based adjustment, is associated with a lower emissivity value that increases the correction. On the other hand, the $50-\mu \mathrm{m}$ assumption, carrying a larger geometry-based adjustment, is associated with a higher emissivity value that decreases the adjustment. These factors are included in the temperature adjustment example given in Table 4 above.

One additional factor that tends to produce a compensating effect in the temperature adjustment regimen is the question of the assumed extinction coefficient for the coal matter. Although the literature is replete with various kinds of infrared spectra for a wide range of coals, very few are on thin sections so that an extinction coefficient can easily be extracted. The value of $15 \mu \mathrm{m}$ for the optical depth of the starting coal is taken from early Bureau of Mines data on thin sections, ${ }^{43}$ but not for the same Illinois No. 6 coal that concerns us here. (A similar value was also inferred from the emissivity data of Fletcher and coworkers. ${ }^{15}$ ) However, if the extinction coefficient (for 7- to 12- $\mathrm{mm}$ radiation in the original coal material) either were substantially higher than we have inferred from literature data or were to rise significantly during mild pyrolysis (i.e., if the swelling particles did not decrease in optical thickness) then the steady-state temperature and radiance of the particles would rise as the particles swell. The hottest appearing particles would then be the largest particles, and the appropriate adjustments of these raw temperatures would be smaller than those used here, because of both the larger size and the higher emissivity. In other words, if either assumption about the extinction coefficient of the coal matter were wrong, we would have overcorrected the raw temperature data. Thus, the temperatures are not likely to be higher than those represented by the upper edge of the band indicated by the dotted lines in Figure 9; that is, we judge that the true temperature distribution is well represented by a line through the middle of this band at $\pm 50^{\circ}-75^{\circ} \mathrm{C}$.

Finally, we compare the measured temperatures with the threshold of visibility to the human eye. For the run depicted in Figure 9 (above) as the dotted lines (and shown in Table 4), at $98 \%$ (cumulative particle percentage), the upper temperature limit was determined to be $630^{\circ} \mathrm{C}$. In this run there were no visibly glowing particles. In two companion runs, in which roughly $15 \%$ and $2 \%$ of the particles were glowing, the same temperature determination regimen showed the upper $1-2 \%$ of the particles to be $\leq 940^{\circ}$ and $770^{\circ} \mathrm{C}$, respectively. These latter two temperatures are 
consistent with a threshold of visibility of about $850^{\circ} \pm 50^{\circ} \mathrm{C}$, dependent on object size, velocity and background illumination. Similarly, these total radiance-based measurements merge quite well (within about $40^{\circ} \mathrm{C}$ ) with those made by using a disappearing filament pyrometer, a multicolor instrument that is quite accurate when appropriately used.

To summarize particle temperature measurement considerations, we conclude that the excellent product separation and collection capability of the entrained-flow laser-pyrolysis system, coupled with precise measurement of the char particle size distribution and careful consideration of the appropriate way to combine the raw temperature data, have made it possible to determine the distribution of steady-state temperatures within $\pm 75^{\circ} \mathrm{C}$.

\section{RAPID BATCH PYROLYSIS TO INTERMEDIATE TEMPERATURES}

Heating of sealed fused-silica ampules in a molten-salt bath provides a convenient way of rapid heating to intermediate temperatures $\left(400^{\circ}-500^{\circ} \mathrm{C}\right)$. This approach was combined with a modified procedure for pretreating coals with hydrogenated tars. Following the tar loading, the coals were heated to $200^{\circ} \mathrm{C}$ for $30 \mathrm{~min}$ in a sealed microautoclave to pre-swell them or otherwise to achieve benefits similar to the je reported by Miura and coworkers for the pyrolysis of coals preswollen in tetralin. ${ }^{4}$ The rationale for this approach (which is tantamount to "liquefaction" in minimal solvent) and its results are detailed below. Although we consider this approach well founded, we did not observe enhanced tar yields that exceeded the experimental scatter.

Pre-Swelling of Treated Coals. Recently Miura and coworkers ${ }^{4}$ reported results that appear highly relevant to the pretreatment approach taken in this project. Their work involved the flash pyrolysis of coals that had been swollen in tetralin vapors at temperatures above ambient but well below pyrolysis (i.e., at $\sim 250^{\circ} \mathrm{C}$ ). Their finding was essentially that even after all the tetralin had been removed, a significant residual effect (attributed by the authors to irreversible swelling) led to enhanced production of volatiles on subsequent pyrolysis. A typical result was that curie point flash pyrolysis (at $760^{\circ} \mathrm{C}$ ) of a Japanese subbituminous coal "soaked" in tetralin at $250^{\circ} \mathrm{C}$, followed by removal under vacuum of all but about 10-20 wt \% of the tetralin from the coal, resulted in an approximate $30 \%$ increase ( $\sim \mathrm{wt} \%$ of maf coal) in tar yield when the coal was pyrolyzed in flowing nitrogen at $760^{\circ} \mathrm{C}$. If the soaking took place at less than $100^{\circ} \mathrm{C}$, the additive was much less effective.

Miura et al. further reported that the increase in tar yield almost doubled when the same pyrolysis of pretreated coal was performed under $1000 \mathrm{psi}$ of hydrogen. While yield improvement in the presence of $\mathrm{H}_{2}$ is not surprising for a coal-conversion process, it is for a flash-pyrolysis process at relatively mild temperatures: various pyrolysis studies 46 have shown that at 
temperatures below about $600^{\circ} \mathrm{C}, \mathrm{H}_{2}$ pressures below $\sim 500 \mathrm{psi}$, and short reaction times, the effect of $\mathrm{H}_{2}$ is actually detrimental (compared with pyrolysis in vacuum). Consistent with these previous studies, Miura's data for the untreated coal show a decrease in tar yield as the $\mathrm{H}_{2}$ pressure is increased from $1 \mathrm{~atm}$ to $1000 \mathrm{psi}$. we conclude that the presence of the added hydroaromatics in the preswollen allows the coal to take advantage of hydrogen pressure under conditions that would otherwise lead to a negative effect. These results led us to the following conclusions and suggestions, some of which we tested with the modified pretreatment and pyrolysis approach described below.

- Because larger PCAHs are known to be much better hydrogen donors than tetralin, Miura's beneficial results obtained with tetralin alone suggest that our coal-tar pretreatment approach should provide even greater increases in volatiles yields under the right conditions.

- Because soaking the coal in tetralin at temperatures $100^{\circ}$ to $200^{\circ} \mathrm{C}$ above ambient is required to substantially benefit the subsequent pyrolysis, soaking the tar-pretreated coals at $100^{\circ}$ to $200^{\circ} \mathrm{C}$ might substantially improve the beneficial impact of tar pretreatment.

- Because the moderate-temperature soak allowed hydrogen pressure in the subsequent pyrolysis to have a positive impact on tar yields (under time-temperature conditions that would otherwise have a negative effect), this result should be even more true for PCAHs, which are kncwn to better utilize gaseous $\mathrm{H}_{2}$ in coal liquefaction.

Supported by the above rationale, we used the procedure described below to load coals with "mild gasification aids" and, at the same time, to perform the moderate temperature "heat soak."

Modified Pretreatment Procedure. A satisfactory procedure for producing pretreated coal in batches of the size needed for laboratory testing (i.e., about $2 \mathrm{~g}$ ) was developed after several iterations. A fused-silica liner was used to facilitate removal of the treated coal from the 3/4-in.-o.d. tubing bomb heat-treatment reactor. Several grams of ground and sized coal were spread evenly along the bottom half of a horizontally held liner. Tar solution was then added evenly to the layer of coal to the point of incipient wetness to ensure even distribution of the additive. The liner is weighed, placed in the pressure vessel, pressurized with 500 psi $\mathrm{N}_{2}$, and heated for $30 \mathrm{~min}$ at $215^{\circ} \mathrm{C}$. After cooling, the reactor is vented, and the liner is removed and weighed (there was no movement of coal or tar to the outer surfaces of the liner or to the steel jacket). Excess tetralin was then removed at $60^{\circ} \mathrm{C}$ and $\sim 1$ torr until the coal was free-flowing (once the tar-bonded aggregates were broken up). A free-flowing solid was obtained after removal of about one-half to three-quarters of the originally added tetralin. In an effort to maximize the impact of the pretreatment and to simplify subsequent analytical distinction between volatilized pretreatment additive and volatiles derived directly from the coal, pretreated coals were also 
prepared with hexahydropyrene to represent the most beneficial components in a hydrotreated coal tar.

The effect of these pretreatments was tested with two coals in small-batch pyrolysis experiments, as described below. Testing of the pretreatment with laser pyrolysis was not performed (1) because of limitations in time and funds and (2) because the batch reactor results turned out to be less promising than we had hoped.

Low-Temperature Pyrolysis of the Pretreated Coals. One of the principal reasons for developing the laser-pyrolysis technique, with its unique cool gas environment, was to reduce the potential of secondary reactions. In addition to the low-temperature environment, the flowing gas sweeps away the volatiles as they are released, further minimizing the opportunity for retrogressive reaction of the volatiles with the residual char. On the other hand, if pretreating coal with additives that can increase volatiles production is a specific goal, those additives must remain with the coal during the critical reaction period. Our purpose in choosing a mixture of hydrogenated PCAHs (such as those present in some hydrotreated coal tars) for coal pretreatment was to take advantage, in the context of mild gasification, of the known ability of hydroaromatics to induce the cleavage of strong bonds. Therefore, we speculated that this purpose might be better served by pyrolysis at a lower temperature, where volatiles are more confined, than during pyrolysis in 1 atm of an entraining gas. Accordingly, we performed a series of experiments involving moderately rapid pyrolysis of pretreated, "preswelled" coals in small, thin-walled ampules.

Pyrolysis Procedure. This procedure involves sealing the coal sample in small fusedsilica ampules, followed by pyrolysis in a constant-temperature molten-salt bath. The ampules were made from 3-mm-i.d., 0.5-mm wall tubing; fused silica was used primarily because it minimizes the strain introduced during sealing and when the ampules are plunged into the moltensalt bath.

The thin wall provides the fastest heat-up time available in an experiment of this type. Assuming that heat transfer through the glass wall is the limiting factor, a thermal diffusivity of $0.05 \mathrm{~cm}^{2} / \mathrm{s}$ gives a relaxation time of $0.025 \mathrm{~s}$, suggesting 47 that the inside wall will reach within $\sim 1^{\circ} \mathrm{C}$ of the final temperature in about $6 \times 0.025 \mathrm{~s}$, or $0.15 \mathrm{~s}$. For a tube large enough to have multiple layers of coal particles, particle-to-particle heat transfer will be the slow step, and only in a tube with a very small internal diameter will any but those layers of particles closest to the tube walls approach the heat-up time estimated above. We chose 3-mm-i.d. tubes as a compromise between heat-up rate and bursting pressure on the one hand and sample capacity on the other. 
Tubes of this size allow 50 to $100 \mathrm{mg}$ to be used conveniently in a tube several inches long. We expect that, even in this larger size tube, the sample will reach reaction temperature within $5 \mathrm{~s}$.

Initial experiments in which the entire ampule was immersed in the molten salt resulted in ampoule failure caused by overpressure during devolatilization. In a second iteration, the pyrolysis procedure involved using a small tube holder that holds only a predetermined portion of the ampules beneath the melt surface. Partial immersion served the dual purpose of (1) keeping the pressure low enough for most coals to prevent bursting of the tubes and (2) acting as a retort and removing the condensable volatiles from the hottest part of the ampule. Removal of lowmolecular-weight condensables from the hot zone is important, because $490^{\circ} \mathrm{C}$ exceeds the critical point of many of the low molecular weight products. A constriction was made in the ampule which was positioned just below the liquid surface. This constriction was necessary to prevent a large fraction of the coal from bumping into the void space above the liquid surface when the initial volatiles were released. This procedure resulted in a refluxing layer 1 to $2 \mathrm{~cm}$ above the salt bath surface and prevented bursting for all four coals tested thus far, except Wyodak. The bath temperature may just be too far above the critical temperature of water for the ampules, even with a cooler portion, to accommodate the amount of water generated by low-rank coals.

When the reaction time was completed, the ampules were quenched in a water bath. The extract or tar was defined as material passing a $0.2-\mathrm{mm}$ PTFE filter after dissolution of the ampule contents, with sonication, in $20-\mathrm{ml}$ mixtures of $70 \% \mathrm{CH}_{2} \mathrm{Cl}_{2}$ and $30 \% \mathrm{MeOH}$ at $40^{\circ} \mathrm{C}$. For original sample sizes of $\sim 70 \mathrm{mg}$, this procedure was satisfactorily reproducible in terms of mass balance: The total of gases and losses was reasonably constant in repeated runs, but the precision was not quite as good for the extracted tars.

Batch Pyrolysis Results. The results obtained thus far for pyrolysis of raw and pretreated coals at temperatures of $450^{\circ}$ and $490^{\circ} \mathrm{C}$ are shown in Table 5. The yield of material extractable from a methylene chloride-methanol mixture (after correction for the added tar or hexahydropyrene) appears on the average to increase slightly (20\% for tar-loaded PSOC 1098), but this increase is not outside the scatter of the extract yields. Thus, while this set of data is not large enough to justify a definitive statement, it does fail to indicate that confined pyrolysis following hydrotreated tar (or hexahydropyrene) pretreatment results in any clear improvement in tar-yield enhancement compared with the $10-20 \%$ enhancements already obtained with vacuum TGA or laser pyrolysis of room-temperature pretreated coals. 


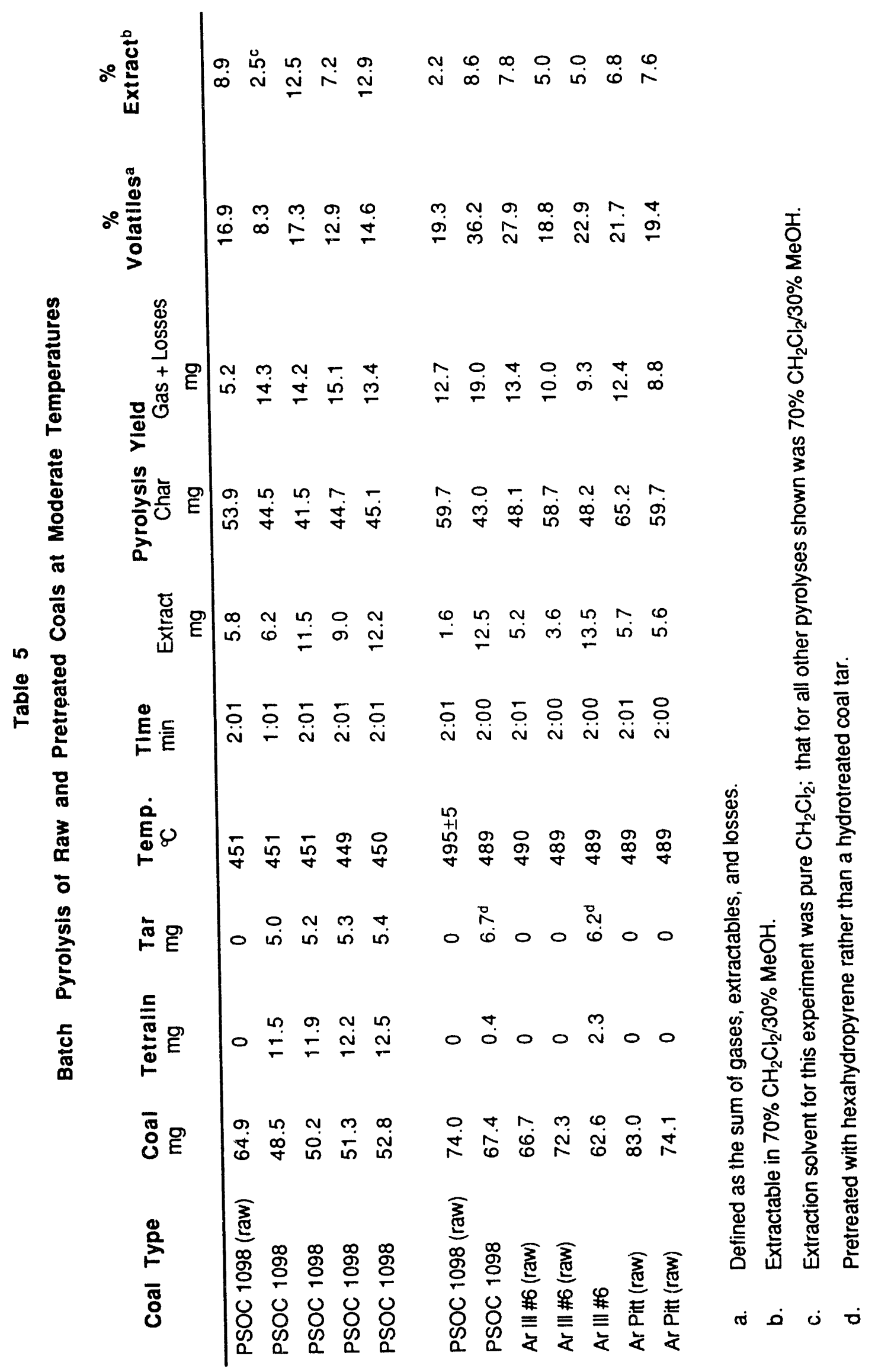


It was disappointing not to find clear benefits under these batch pyrolysis conditions; even though we were not able to perform the pyrolysis in the presence of $\mathrm{H}_{2}$, when Miura saw additional benefits, we had hoped to find larger tar increases than those we previously reported for laser pyrolysis and vacuum TGA pyrolysis conditions. We can easily invoke reasons why the benefits of treating coals with small amounts of hydroaromatics would be expected on one hand to be marginal or on the other hand to be substantial. The improved yields might be marginal because this approach could be described as liquefaction in the presence of a minimum of solvent, and solvent-to-coal ratios substantially less than 1.0 are known to be very ineffective. On the other hand, under mild gasification conditions, volatiles are produced through bond breaking in which the only hydrogen available is that from hydrogen-rich portions of the coal structure. Thus, even a small addition of extra hydrogen or effective hydrogen transfer agents might be expected, under the right conditions, to result in significant increases in volatile yields. In any case, it is evident that in these sealed-ampule pyrolyses, such conditions were not achieved for the three coals tested. 


\section{CONCLUSIONS}

The significant accomplishments and findings of this research are listed below.

\section{Laser-Pyrolysis Development}

- We designed, assembled, and tested a laser-heated entrained-flow system that maintains a steady flow of coal particles in a fine stream $(\sim 4 \mathrm{~mm}$ in diameter) of inert gas traveling upward at velocities of a few centimeters per second, then efficiently separates the char from the tar in a cyclone and filter train.

- We measured particle temperatures using optical pyrometry and imaging with an infrared video camera. The particles achieve a distribution of temperature maxima that is largely governed by their original size.

\section{Mechanism and Kinetics of Volatiles Release}

- FIMS analysis of evolved tars suggests that under rapid heat-up conditions, a substantial portion of the tar evolution results from liquid transport rather than from an evaporative process.

- The levels of phenols and dihydroxy phenols in laser-pyrolysis tars are substantially higher than in other entrained-flow reactor tars, in part as a result of fewer retrograde reactions involving these reactive products.

- Tar production in laser pyrolysis is extremely rapid, with tar release times of less than $50 \mathrm{~ms}$ even at temperatures as low as $500^{\circ} \mathrm{C}$.

- Tar yields are significantly higher from laser pyrolysis than from some other entrained-flow laboratory pyrolysis techniques, and the yields for subbituminous coals approach those for bituminous coals, in contrast to the case with slower heating methods, from which the yields for subbituminous coals tend to be much lower.

\section{Effect of Tar Loading}

- With slow-heating pyrolysis techniques (Py-FIMS and TGA), tar pretreatment did not result in improved volatiles yields; but with a "rapid"-heating $\left(600^{\circ} \mathrm{C} / \mathrm{min}\right.$; final temperature, $450^{\circ} \mathrm{C}$ ) vacuum TGA technique, 10 to $30 \%$ increases in volatiles yields were observed for a Wyodak coal, an Illinois No. 6 coal, and a Pittsburgh coal.

- Pyrolysis in a tubing bomb using a molten-salt bath at $490^{\circ} \mathrm{C}$ did not result in significantly enhanced tar yields from an Illinois No. 6 (PSOC 1098) coal loaded with hexahydropyrene and partially hydrogenated coal tar. 
- With laser pyrolysis, tar pretreatment results in a $20 \%$ decrease in volatiles yield from an Illinois No. 6 coal but a $20 \%$ increase from a Pittsburgh coal when the steady-state temperature is in the region of $840^{\circ}-880^{\circ} \mathrm{C}$.

The rates and temperature dependence observed during laser pyrolysis of coal are not reconcilable with activation energies for tar generation as high as to 30 to $50 \mathrm{kcal} / \mathrm{mol}$ often reported for ramped-temperature coal pyrolysis. Furthermore, the very rapid laser-heating we have used approximates a temperature-jump condition where the widely used model of distributed activation energies for a set of parallel first-order reactions can no longer be a valid explanation for apparent activation energies lower than those expected for any of the individual first order reactions. In other words, the data obtained here appear incompatible with individual component activation energies in the 50 to $65 \mathrm{kcal} / \mathrm{mol}$ range that would be representative of rate limitation by weak-bond homolysis. On the other hand, the results are generally supportive of a mechanistic picture in which tar generation doe not result form spontaneous thermal scission of weak bonds, but is the result of a complex sequence of hydrogen-transfer reactions.

The high tar yield seen in this work, where the entire volume of the coal particle becomes hot and fluid at very nearly the same time, taken together with the evident non-vapor transport of the tar under these conditions, emphasizes the importance of better understanding the development of fluidity during coal heating. This specifically includes the profound effects-long-recognized but poorly understood - that mild oxidation has in suppressing coal fluidity. It also includes the more recently recognized fact that heating in the presence of an inert gas produced substantially greater fluidity than does heating in the presence of combustion gases, even if the conditions are very fuel rich and all the oxygen itself has already been consumed when the coal particles are encountered. A better understanding of these fluidity phenomena carries substantial implications for improvement of mild gasification under practical oxidation conditions.

In more general terms, if one wishes to have engineering models for volatiles production (whether they are to be used for guiding experimental work in pulverized coal combustion or whether they are to be used for process improvement in mild gasification) that are based on a correct picture of the chemistry of tar generation and transport, then these results clearly call for further coal pyrolysis studies with well controlled, very rapid radiant heating, but with temperature measurement improved further, from what we were able to accomplish within this project. 


\section{PUBLICATIONS RESULTING FROM THIS PROJECT}

Following is a list of publications to date resulting from work under this contract. Those aspects of the research already described in these publications are not repeated in detail, but only briefly summarized on this report.

1. A COMPARISON OF LIQUIDS PRODUCED FROM COAL BY RAPID AND SLOW HEATING PYROLYSIS EXPERIMENTS. Khan, M. R.; Serio, M. A.; Malhotra, R.; Solomon, P. R., Am. Chem. Soc., Div. Fuel Chem. Preprints, 1989, 34(4), 1054.

2. CHARACTERIZATION OF THE ARGONNE PREMIUM COAL SAMPLES BY FIELD IONIZATION MASS SPECTROMETRY. Malhotra, R.; McMillen, D. F.; Huestis, D. L. Am. Chem. Soc., Div. Fuel Chem. Preprints, 1991, 36(3), 1252.

3. PYROLYSIS OF COALS LOADED WITH POLYCYCLIC AROMATIC

HYDROCARBONS. Maihotra, R.; St. John, G. A.; Tse, D. T.; McMillen, D. F., Am. Chem. Soc., Div. Fuel Chem. Preprints 1988, 33(2), 257.

4. LASER PYROLYSIS OF AN ENTRAINED STREAM OF COAL PARTICLES. Smith, M. W.; McMillen, D. F.; Malhotra, R.; .Platz, R. M., Am. Chem. Soc., Div. Fuel Chem. Preprints, 1990, 35(2), 455.

5. LASER PYROLYSIS OF AN ENTRAINED STREAM OF COAL PARTICLES. Smith, M. W.; Malhotra, R.; McMillen, D. F.; McEwen, A. B.; Platz, R. M. Proceedings of the 1991 Conference on Coal Science, Butterworth-Heinemann, Ltd., 1991, p. 496. 


\section{REFERENCES}

1. McMillen, D. F.; Malhotra, R.; Nigenda, S. E., Fuel, 1989, 68, 380.

2. Poutsma, M. L.; Energy Fuels, 1990, 4, 113

3. Hüttinger, K. J.; Sperling, R. E., 1987, "Flash Hydropyrolysis of Coals Doped with Aromatics", in 1987 International Conference on Coal Science, Elsevier, Amsterdam, p. 699.

4. Miura, K.; Mae, K.; Yoshimura, T.; Hashimoto, K., Am. Chem. Soc., Div. Fuel Chem. Preprints 1989, 34(4), 1071.

5. Mochida, I.; Itoh, K.; Korai, Y.; Shimohara, T.; Fuel, 1986, 65, 429.

6. Serio, M. A.; Hamblen, D. G.; Markham, J. R.; Solomon, P. R., Energy Fuels, 1987, 1, 138.

7. Gibbins-Matham, J. R.; King, R.A.V.; Wood, R. J.; Kandiyoti, R.; Rev. Sci. Instrum. 1989, 60, 1129.

8. Solomon, P. R.; Serio, M. A., "Evaluation of Coal Pyrolysis Kinetics," presented at NATO Workshop on Fundamentals of Physical Chemistry of Pulverized Combustion, Les Arcs, France, July 28 - August 1, 1986.

9. Johnson, G. R.; Murdoch, P.; Williams, A., Fuel, 1988, 67, 834.

10. Solomon, P. R.; Serio, M. A.; Carangelo, R. M; Markham, J. R., Fuel, 1986, 65, 182.

11. Khan, M. R.; Serio, M. A.; Malhotra, R.; Solomon, P. R., Am. Chem. Soc., Div. Fuel Chem. Preprints, 1989, 34(4), 1054.

12. Malhotra, M.; McMillen, D. F.; Huestis, D. L., Am. Chem. Soc., Div. Fuel Chem. Preprints, 1991, 36(3), 1252.

13. Malhotra, R.; St.John, G. A.; Tse, D. T.; McMillen, D. F., Am. Chem. Soc., Div. Fuel Chem. Preprints 1988, 33(2), 257.

14. Fletcher, T. H.; 1987a, "Measurement of Coal Particle Temperatures During Devolatilization," Sandia Combustion Research Program Annual Report, SAND88-8004, UC-96, p. 8-2.

15. Fletcher, T. H.; Baxter, L. L.; Ottesen, D. K., Am. Chem. Soc., Div. Fuel Chem. Preprints $1987,32(3), 42$.

16. Serio, M. A.; Solomon, P. R.; Charpenay, S.; Yu, Z-Z.; Bassilakis, R., Am. Chem. Soc, Div. Fuel Chem. Preprints, 1990, 35(3), 808. 
17. Solomon, P. R.; Serio, M. A.; Carangelo, R. M.; Bassilakis, R.; Gravel, D.; Baillargeon, M.; Baudais, F.; Vail, G.; Energy Fuels, 1990, 4, 319.

18. Freihaut, J. D., Proscia, W. M.; Seery, J. D., Energy Fuels 1989, 3, 692.

19. Solomon, P. R.; Haubler, D. G., Serio, M. A., Smoot, L. D., Brewster, B. S.;

"Measurement and Modeling of Advanced Coal Conversion Processes," Annual Report, DOE, METC, under Contract No. DE-AC21-86MC23075, October, 1987.

20. Gibbins, J. R.; Kandiyoti, R., Energy Fuels, 1988, 2, 505.

21. Smith, M. W.; McMillen, D. F.; Malhotra, R.; Platz, R. M. Am. Chem. Soc., Div. Fuel Chem. Preprints, 1990, 35(2), 455.

22. Schlosberg, R. H.; Davis, W. H. Jr.; Ashe, T. R., Fuel, 1981, 60, 201.

23. McMillen, D. F.; Malhotra, R.; Chang, S.-J.; Nigenda, S. E., Am. Chem. Soc., Div. Fuel Chem. Preprints, 1985, 30(4), 414.

24. Oh, M. S.; Peters, W. A.; Howard, J. B., AIChE J., 1989, 35, 775.

25. Niksa, S.; Kerstein, A. R., Am. Chem. Soc., Div. Fuel Chem. Preprints, 1989, 34(4), 1293.

26. Gray, V. R.; Fuel, 1988, 67, 1298.

27. Suuberg, E. M.; Unger, P. E.; Lilly, W. D., Fuel, 1985, 64, 956.

28. Gat, N.; Cohen, L. M., Denison, M. R., Witte, A. B., "Effect of Rapid Heating on Coal Nitrogen and Sulfur Release," Final Report, US DOE Contract No. DE-AC22-81 PC40273.

29. Gat, N.; Combust. Sci. Tech. 1986, 49, 297.

30. Gat, N.; Cohen, L. M.; Witte, A. B.; Denison, M. R., "Coal Pyrolysis Under Rapid Heating with a CW Laser," presented at the Central States Section of the Combustion Institute Meeting, Lexington, Ky, March 1983.

31. Maloney, D. J.; Monazam, E. R.; Woodruff, S. D.; Lawson, L. O., Am. Chem. Soc., Div. Fuel Chem. Preprints, 1990, 35(3), 721.

32. Monazam, E. R.; Maloney, D. J.; Lawson, L. O., Rev. Sci. Instrum., 1989, 60, 3460.

33. Phuoc, T. X.; Maloney, D. J., in Twenty-Second Symposium (International) on Combustion, The Combustion Institute, Pittsburgh, Pa, 1988, p. 125.

34. Tognotti, L.; Longwell, J. P.; Sarofim, A. F., in Twenty-Third Symposium (International) on Combustion, The Combustion Institute, Pittsburgh, Pa, 1990, p. 1207.

35. Maswadeh, W.; Arnold, N. S.; Meuzelaar, H.L.C., Am. Chem. Soc., Div. Fuel Chem. Preprints, 1990, 35(3), 713.

36. Gat, N.; Cohen, L. M.; Witte, A. B., "Three-Color Pyrometer for Burning Particle Temperature Measurement," presented at the JANNAF Combustion Meeting, Monterey, Calif., October 1983. 
37. Fletcher, T. H., private communication, 1991.

38. Freihaut, J. D., private communication, 1991,

39. Anthony, D. B.; Howard, J. B.; Hottel, H. C.; Meissner, H. P., in Fifteenth Symposium (International) on Combustion, The Combustion Institute, Pittsburgh, Pa, 1975, p. 1303.

40. Radzioch, S.; Hawksley, P.G.W., Ind. Eng. Chem., Process Design Dev., 1970, 9, 521.

41. Freihaut, J. D., Ph. D. Thesis, Pennsylvania State University, 1980.

42. Solomon, P. R.; Carangelo, R. M; Best, P. E.; Markham, J. R.; Hamblen, D. G., Fuel, 1987, 66, 897.

43. Friedel, R. A.; Queiser, J. A., Anal. Chem., 1956, 28, 22.

44. Green, P. D.; Patrick, J. W.; Thomas, K. M.; Walker, A., Fuel, 1985, 64 , 1431.

45. Pohl, J. H.; Kobayahi, H.; Sarofim, A. S., "Effects of Temperature and Time on Swelling of Pulverized Coal," presented at the Combustion Institute Western Section Technical Meeting, Boulder, Colo., April 17-18, 1978.

46. Howard, J. B., "Fundamentals of Coal Pyrolysis and Hydropyrolysis," in Chemistry of Coal Utilization, Second Supplementary Volume, M.A. Elliott, Ed. (John Wiley and Sons, New York, 1981) p. 765.

47. Brower, K. R.; Oxley, J. C.; Tewari, M., J. Phys. Chem. 1989, 93, 4029. 

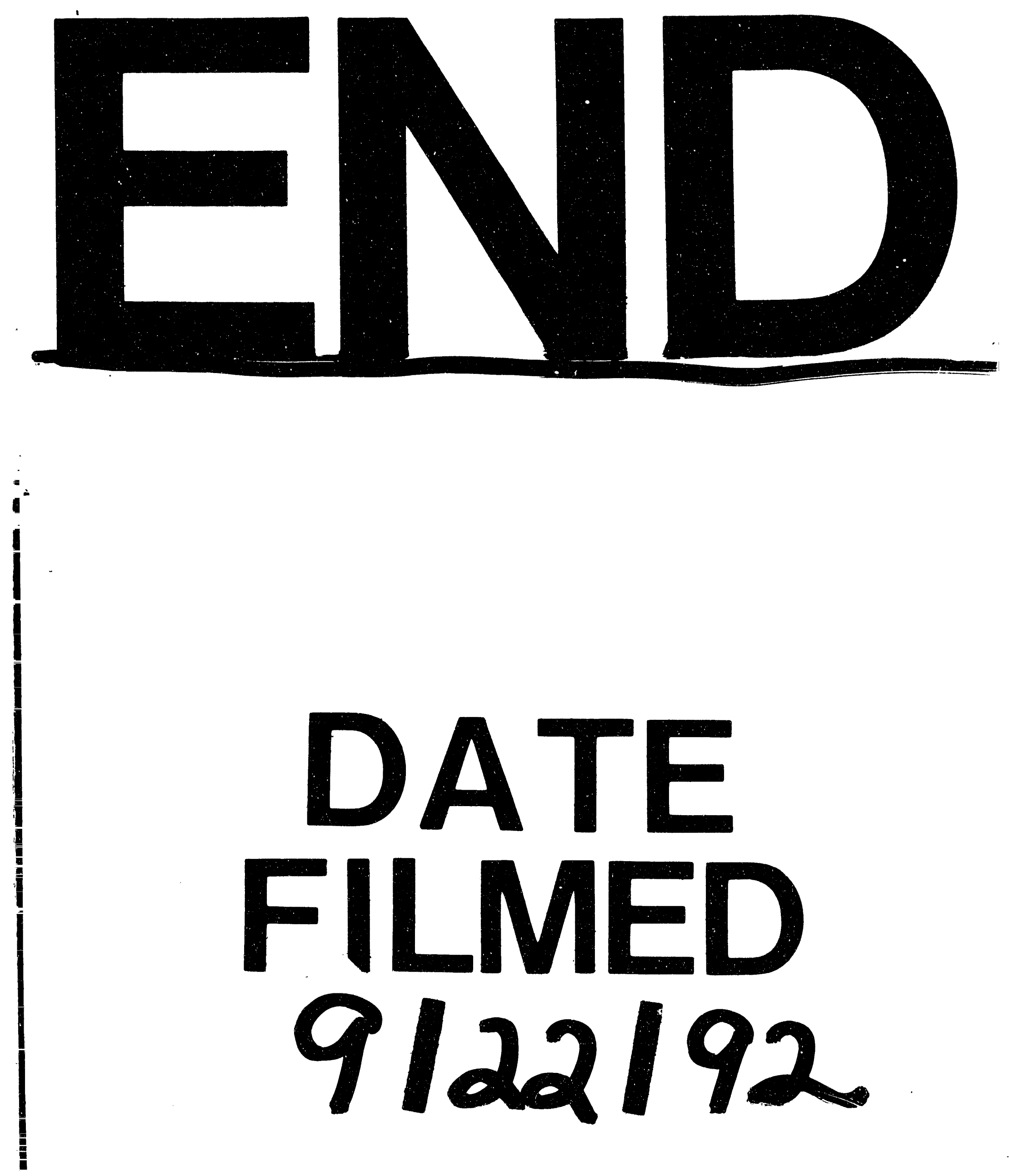